\title{
A vulnerability index formulation for the seismic vulnerability assessment of vernacular architecture
}

\author{
Javier Ortega $^{\mathrm{a}, *}$, Graça Vasconcelos ${ }^{\mathrm{a}}$, Hugo Rodrigues ${ }^{\mathrm{b}}$, Mariana Correia ${ }^{\mathrm{c}}$ \\ ${ }^{a}$ ISISE, Department of Civil Engineering, University of Minho, Guimarães, Campus de Azurém, 4800-058 Guimarães, Portugal \\ ${ }^{\mathrm{b}}$ RISCO, School of Technology and Management, Polytechnic Institute of Leiria, Campus 2, 2411-901 Leiria, Portugal \\ ${ }^{\mathrm{c}}$ CI-ESG Research Centre, Escola Superior Gallaecia, Vila Nova de Cerveira, Portugal
}

\section{A R T I C L E I N F O}

\section{Keywords:}

Seismic vulnerability assessment

Vulnerability index

Vernacular architecture

Numerical analysis

Pushover parametric study

Multiple regression analysis

Expert opinion

\begin{abstract}
A B S T R A C T
The valorization and preservation of vernacular architecture, as well as traditional construction techniques and materials, is a key-element for cultural identity. Conservation efforts are often mainly focused on historical constructions and monuments. Furthermore, more detailed and sophisticated seismic vulnerability assessment approaches typically used for monumental buildings require time, cost and resources that are not commonly assigned to the study of vernacular architecture. Earthquakes come unexpectedly, endangering in-use vernacular architecture and the population who inhabits it. That is why simplified methods for the seismic vulnerability assessment of vernacular architecture are of paramount importance. The present paper presents a new formulation for the vulnerability index method particularly adapted to the characteristics of vernacular architecture: Seismic Vulnerability Index for Vernacular Architecture (SVIVA). The vulnerability index method has been used extensively in the literature using different formulations that were always defined based on empirical knowledge acquired through post-earthquake damage observation and expert judgment. The SVIVA formulation is developed by means of an analytical process instead of the traditional empirical approach. The process included an extensive numerical modeling campaign that allows adapting the method to the characteristics of vernacular architecture by gaining a deeper quantitative knowledge on their seismic behavior.
\end{abstract}

\section{Introduction}

Vernacular architecture is the result of a tight relation between humans and the environment. When local communities have to build their dwellings, they respond to their surrounding environment and climate, through empirical knowledge acquired along generations. Vernacular architecture reflects the tradition and life style of a community, and the inhabitants' bonding with the natural environment. As a result, vernacular architecture is extremely heterogeneous, responding to local conditions. However, the use of technological and standardized modern materials has homogenized the way of building throughout the world, providing an architecture that can be observed in any geography, jeopardizing the local building culture and vernacular architecture. For this reason, the valorization and preservation of the vernacular heritage, as well as the traditional construction techniques and materials is crucial, not only as a key element of cultural identity and a witness of the past, but also as a privileged factor for local development, boosting local economies $[1,2]$.
Vernacular architecture located in seismic prone areas can be particularly vulnerable to earthquakes due to a scarcity of resources in generally poor communities, resulting in inadequate overall structural layout of the construction, the use of poor materials, the lack of proper constructive details and a poor maintenance. Earthquakes come unexpectedly, endangering in-use vernacular architecture and the population who inhabits it. There is a critical gap in knowledge regarding vernacular architecture earthquake preparedness, since research in vernacular architecture has predominantly been focused on building typologies and spatial organization. The study of the seismic behavior and vulnerability of representative vernacular construction systems has traditionally been ignored, and conservation efforts have been mainly placed on historical architecture and monuments. Despite this, there has been a growing interest on the seismic behavior of vernacular architecture in the recent years, involving: (a) the experimental characterization of different vernacular construction systems [3-9]; (b) insitu post-earthquake damage observations [10-13]; or (c) the seismic assessment of different vernacular typologies using numerical analysis

\footnotetext{
* Corresponding author.

E-mail addresses: javier.ortega@civil.uminho.pt (J. Ortega), graca@civil.uminho.pt (G. Vasconcelos), hugo.f.rodrigues@ipleiria.pt (H. Rodrigues), marianacorreia@esg.pt (M. Correia).
} 

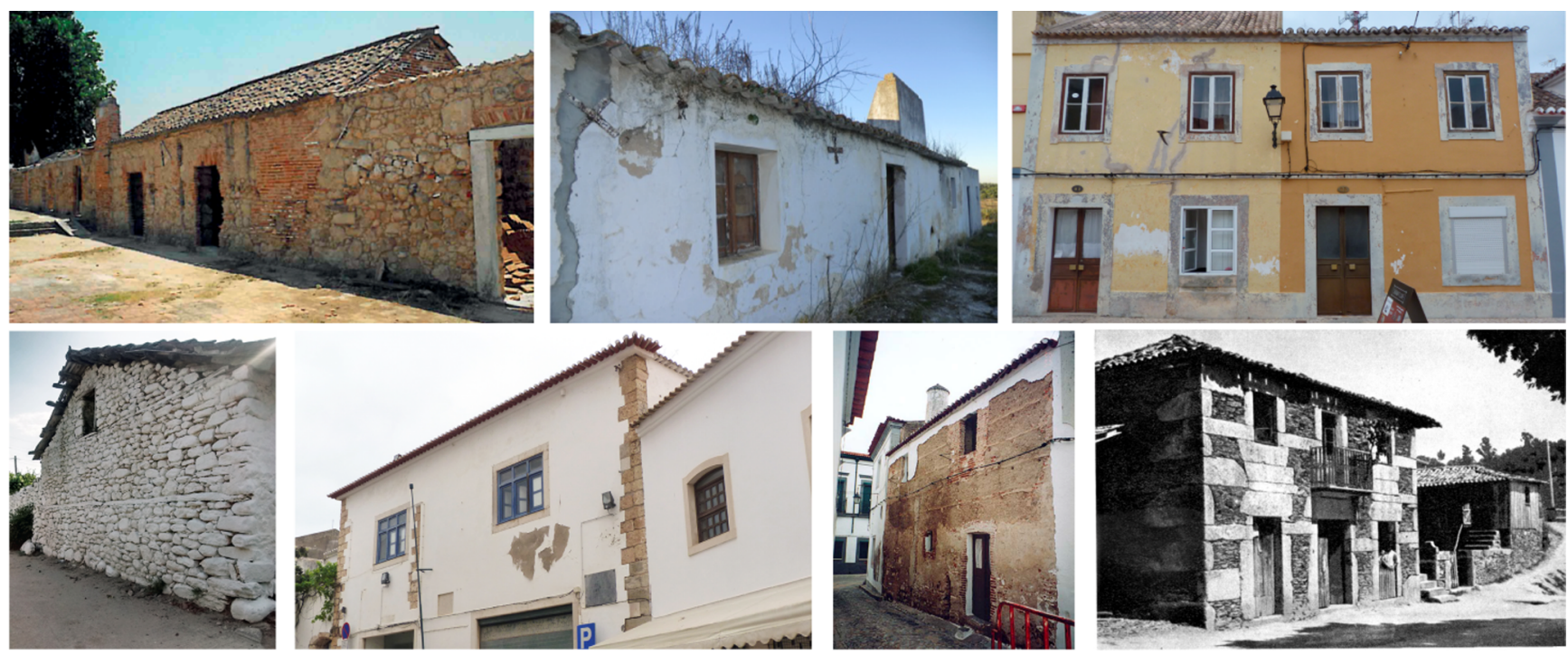

Fig. 1. Examples of targeted vernacular architecture of the SVIVA formulation.

and analytical procedures [14-17], or empirical correlations between damage and ground motion developed after the occurrence of different earthquakes for specific vernacular construction typologies [18-20]. The seismic assessment of the built vernacular heritage requires a deep knowledge and investigation of the place, traditional techniques and materials. However, the time, cost and resources required to obtain a sufficient in-depth level of information of the analyzed structure are not commonly assigned to the study of vernacular architecture. That is why the development of an expedited method for the seismic vulnerability assessment of vernacular architecture is of paramount importance, since more detailed and sophisticated approaches are typically restricted for individual monumental buildings.

The present paper shows the development of a new formulation for the vulnerability index method firstly proposed by Benedetti and Petrini [21] particularly adapted to the characteristics of vernacular architecture and referred as: Seismic Vulnerability Index for Vernacular Architecture (SVIVA). In particular, the targeted vernacular architecture of the SVIVA formulation was initially the Portuguese vernacular heritage, including stone masonry, fired clay brick masonry, adobe masonry and rammed earth constructions (Fig. 1). However, in spite of the peculiarities of Portuguese vernacular architecture, it shares many characteristics with other vernacular constructions throughout the world, especially in the south Mediterranean region. This is particularly evident at a structural level, since the structural system is in most cases conceptually the same and consists of load bearing walls as the main vertical resisting elements. Therefore, the SVIVA formulation is expected to be also applicable to other similar structures outside the Portuguese context.

Vulnerability index methods require the definition of: (a) a number of parameters representing features of vernacular buildings that influence their seismic behavior; (b) seismic vulnerability classes for each parameter; and (c) weights for each parameter. The definition of these three aspects is addressed and presented sequentially within the present paper. Finally, the proposed SVIVA formulation for the vulnerability index method is presented at the end of the paper as the main outcome.

\section{Proposed seismic vulnerability assessment method for vernacular architecture}

The seismic vulnerability of a structure can be defined as its intrinsic proneness to suffer damage as a result of a seismic event. Therefore, the main objective of seismic vulnerability assessments is to measure the probability of a specific building to reach a given level of damage when subjected to a specific seismic action. Seismic vulnerability assessment methods for the built environment, together with hazard analysis (evaluation of the probability of exceedance of a certain level of seismic intensity) and exposure data (inventory of the elements at risk), are the main components of earthquake loss models [22]. Earthquake loss models are meant to predict the consequences of an earthquake quantitatively, in terms of economic impact, repair cost and human casualties. They are an essential tool for seismic risk mitigation because they can save lives and contribute for the preservation of the built heritage, through the evaluation of different mitigation policies and the preparation of immediate emergency response and disaster recovering plans.

\subsection{Brief overview of existing methods}

There exists a wide range of seismic vulnerability assessment methods available in the literature, suitable for different types of analysis with different goals. The selection of a specific method depends on the scale of the analysis and on the level of detail required for the targeted buildings in the area of study [23]. Because of the typical lack of resources (mainly economic) that can be assigned to the study of a traditionally underestimated and precarious vernacular heritage, the method for the seismic vulnerability assessment of vernacular architecture should make use of mostly qualitative data that can be rapidly obtained from simple visual inspections of the buildings. These methods are commonly referred as first level approaches and are particularly well suited for large scale analyses, e.g. urban or national scale, which comprise large numbers of buildings. First level methods are typically based on empirical post-earthquake surveys and expert judgment. Empirical approaches extract correlations between damage and seismic motion after observing the damage suffered by different building typologies due to a particular earthquake [24]. Thus, they require a large set of post-earthquake damage data which is not always available. Methods based on expert judgment emerged as a result of this data limitation [25]. On the basis of expert opinion and previous knowledge, they estimate the damage that a certain structure can suffer for a given seismic intensity by analyzing the structural characteristics of the constructions and classifying them into different building typologies $[26,27]$. 
The method proposed is an adaptation of the hybrid approach followed by Vicente [23], which combines the vulnerability index method [21] and the macroseismic method [28]. Both methods are supported by statistical studies of post-earthquake damage information, but also rely on expert opinion. The vulnerability index method is based on the identification of constructive aspects that are more influential in the seismic structural behavior of the building, which results in the definition of several qualitative and quantitative parameters. The original formulation proposed by Benedetti and Petrini [21] accounted for a total of eleven parameters including, among others, the type of vertical structural system, the type of horizontal diaphragms, the plan configuration and the conservation state. Parameters are related to four classes corresponding to increasing vulnerability, from A (lowest) to D (highest), associated with a qualification coefficient $\left(C_{v i}\right)$. A weight factor $\left(p_{i}\right)$ is included to emphasize the relative importance of each parameter. Each parameter is qualified individually, and the overall vulnerability of the building is calculated as the weighted sum of the parameters, expressed through the vulnerability index $\left(I_{v}\right)$. The vulnerability index is typically normalized to fall within a range between 0 (very low vulnerability) and 100 (very high) and can be understood as a measure of the building safety under seismic loads [29].

The combination of the two methods proposed by Vicente [23] enables to: (a) use the vulnerability index formulation to estimate the seismic vulnerability of the building using predefined parameters, allowing the individual evaluation of the buildings instead of using a general vulnerability class for a specific building typology; and (b) calculate the mean damage grade using the equation proposed by the macroseismic method:

$\mu_{D}=2.5\left[1+\tanh \left(\frac{\mathrm{I}+6.25 \mathrm{~V}-13.1}{Q}\right)\right]$

This analytical expression correlates the expected mean damage grade $\left(\mu_{D}\right)$ and the seismic input, as a function of the building vulnerability, and allows the construction of vulnerability curves for the subsequent seismic vulnerability evaluation and estimation of losses. $I$ is the seismic input in terms of macroseismic intensity, $V$ is the vulnerability index and $Q$ is the ductility index, which is an empirically defined index that considers the ductility of a determined construction typology, typically ranging from 1 to 4 [30]. It should be noted that the vulnerability index used by the two methods ( $I_{v}$ and $V$ ) are different. That is why Vicente [23] proposed another analytical expression relating both measures of vulnerability:

$\mathrm{V}=0.56+0.0064 \times I_{V}$

This approach combining the seismic vulnerability index formulation with the macroseismic method has been recently implemented for the seismic vulnerability assessment of Portuguese masonry structures in several historic city centers [10,30-32], obtaining useful and reliable results as a first level approach. It has also been adapted for other particular structures, such as Nepalese pagoda temples [33].

\subsection{Methodology for the definition of a new formulation for the vulnerability index method}

The proposed SVIVA formulation follows the same structure from the original formulation proposed by Benedetti and Petrini [21]. Thus, three steps were necessary for its development: (a) to identify and define a number of parameters that represent distinctive characteristics of vernacular buildings that influence their seismic behavior; (b) to obtain seismic vulnerability classes for each parameter; and (c) to estimate the weights for each parameter. Once the updated SVIVA formulation is completed, the analytical expressions from Eqs. (1) and (2) can be used to perform a seismic vulnerability assessment. It is noted that the present paper focuses solely on the definition of the updated vulnerability index formulation.

The paper firstly focuses on the selection of the key parameters for the SVIVA formulation, based on literature review. Secondly, a thorough parametric numerical simulation based on detailed finite element (FE) modeling and pushover analysis was designed to support the analysis of the influence of the selected key parameters on the seismic behavior of vernacular buildings. The strategy consists of modifying a reference model according to the different parameters considered and analyzing the variations on the seismic performance of the structure. This procedure led to the definition of the seismic vulnerability classes. Existing formulations for the vulnerability index method have defined vulnerability classes and weights on the basis of empirical knowledge and expert judgment $[21,30,32,34]$. Few studies have combined analytical approaches, such as numerical analysis, to add robustness to mostly empirical methods [33]. However, analytical approaches and complex numerical modeling are suitable to overcome the lack of postearthquake damage data. They are particularly appropriate to carry out parametric studies that allow taking into account the effect of constructive and material characteristics that cannot be typically considered in empirical methods. The use of an analytical procedure to define the SVIVA formulation is the main novelty of the present work and is intended to help existing simplified vulnerability index methods to gain in reliability.

Finally, the definition of the parameters weights that are necessary to complete the SVIVA formulation is carried out following two different approaches: (1) statistical analysis; and (2) expert judgment. The first statistical approach arises from the idea of taking advantage of the large amount of numerical data obtained from the parametric study carried out for the definition of the seismic vulnerability classes. The information of the numerical models, as well as the results from the parametric analyses performed on each of them were organized and structured in a wide database. The weights are then defined through the analysis of the large database previously assembled using multiple linear regression, which led to assess the relative importance of the different parameters. However, the importance of the expert opinion on the evaluation of the weights should not be disregarded. The second approach for the definition of the weights consists of assigning the parameters weight based on expert judgment, which is the common procedure used by existing methods. The expert opinion was collected by means of a questionnaire prepared and distributed among a group of international experts in the field, from around the world. As a result, two sets of seismic vulnerability parameters weights are obtained following the two distinct approaches. A discussion comparing the results obtained using each approach is thus provided. The final SVIVA formulation is presented at the end of the paper.

\section{Definition of seismic vulnerability assessment parameters}

Benedetti and Petrini [21] proposed a set of 11 parameters in their original formulation. Other studies have adapted this formulation to specific structural typologies or to the characteristics of local constructions in specific regions, identifying the most relevant parameters and discarding others that are not considered remarkably significant for those building typologies [30,33,35-37]. Based on the work developed by these authors and on the earthquake performance of vernacular constructions observed in past earthquakes [10,11,13,38-40], a new set of parameters is proposed for the targeted vernacular typologies depicted in Fig. 1. Ten parameters are finally selected according to the singular behavior of this structural type. They are listed in Table 1 showing a brief description and the upper and lower bound of the range of variation considered for each of them.

With respect to the ranges of variation shown in Table 1 , it should be noted that they were determined based on initial reference values 
obtained from the detailed geometrical and constructive survey of typical Portuguese vernacular rammed earth constructions that can be found in Correia [41] and Correia [42]. However, the range of variation is made wider for all parameters in order to cover more vernacular typologies and for the study to be more comprehensive. A more detailed description of the selected parameters is also provided next, which is mainly intended to describe their structural role on the global seismic behavior of vernacular buildings.

\subsection{Wall slenderness $(P 1)$}

The wall slenderness particularly affects the out-of-plane behavior of walls and several authors have already used this parameter to assess the seismic vulnerability of masonry walls $[37,43,44]$. Generally speaking, vernacular buildings walls are rather thick, being rarely thinner than $0.45-0.5 \mathrm{~m}$ thick. The maximum wall height is more variable, even though vernacular buildings tend to be rather compact and present small height dimensions. The range of variation considered for the wall slenderness varies between 4 and 22.5, which may exceed typical values for vernacular constructions, but were adopted for the study to be more comprehensive.

\subsection{Maximum wall span (P2)}

The maximum wall span is another geometrical parameter governing the out-of-plane response of the walls. Vulnerability index formulations including this parameter propose a classification in terms of span to thickness ratio [23]. However, since the wall thickness is already taken into account in the previous parameter, this parameter considers simply the variation of the maximum wall span $(s)$, measured in meters.

\subsection{Type of material (P3)}

With respect to the type of material, the constituent material of vernacular constructions usually consists of stone, fired clay brick, adobe and rammed earth. Masonry fabric typologies can present significant variations in terms of morphology of the masonry wall: (a) type, shape and size of the masonry units (ashlar stone masonry, irregular rubble stone masonry, roughly shaped stone masonry, fired clay brick masonry, etc.); (b) masonry layout (irregular/regular horizontal courses, presence of several leaves, lack of connection between the leaves, etc.); or (c) type of mortar used, if any. These aspects determine the quality of the masonry and, thus, the capacity of the building to withstand horizontal forces resulting from the seismic load, as reported by many authors after post-earthquake observations [45-47]. The mechanical properties of typical masonry and earthen materials used for the construction of walls in vernacular architecture have been studied widely and characterized experimentally on the literature. In order to assess the influence of this parameter, the material properties of the walls are modified based on typical values for these traditional materials collected from the literature [6,48-50]. A series of models were then defined varying the Young's modulus $(E)$, the compressive strength $\left(f_{c}\right)$ and the tensile strength $\left(f_{t}\right)$, adopting values that can be associated to the different materials typically used in vernacular constructions.

\subsection{Wall-to-wall connections (P4)}

Damage observation after earthquakes has shown how the failure mode of the building is characterized many times by vertical cracks at the wall intersections, leading to the out-of-plane overturning or bending failure of the walls. Thus, the quality of the wall-to-wall connections, namely at the building corner and at the connection between external and internal walls, is a key aspect regarding the seismic behavior of the building. In order to evaluate the influence of this parameter in a simple way, the mechanical strength of the elements at the 
corners was reduced to simulate weak connections that are more prone to fail, leading to the independent behavior of perpendicular walls. This way of simulating weak connections at rammed earth buildings represents the difficulty of creating corners inside the frameworks and poor joints with vertical recess solution [51]. For stone masonry buildings, it represents the presence of vertical joints and, thus, the lack of proper interlocking between orthogonal walls.

\subsection{Horizontal diaphragms (P5)}

Horizontal timber diaphragms have a critical role in transmitting the lateral earthquake loads to the vertical resisting elements of the structure. The flexibility of traditional timber floors in unreinforced masonry and earthen vernacular buildings leads to significant bending and shear deformations under horizontal loads [52]. This excessive deformability or lack of proper connections with the load bearing walls forces the walls to work independently, resulting in their local out-ofplane failure when the building is subjected to earthquake loading. However, when effective diaphragm-to-wall connections are ensured, and the in-plane stiffness of the diaphragm is enough to engage the walls parallel to the seismic load, the seismic behavior of vernacular buildings relies on the in-plane response of the walls. Thus, the seismic response of vernacular buildings is strongly dependent on the characteristics of timber diaphragms [17]. Timber floor construction in vernacular architecture is usually very simple, consisting of wooden beams covered with cross boards directly nailed to the beams composing the sheathing. As a result, the behavior of the diaphragm is clearly different in the two orthogonal directions: perpendicular and parallel to the main beam axis. In terms of construction, there are different ways of achieving a proper diaphragm-to-wall connection in both directions. Three aspects were considered as the most critical in defining the seismic behavior of horizontal diaphragms and were evaluated independently in the parametric study: (a) level of connection between timber beams and the perpendicular walls; (b) stiffness of the diaphragm; and (c) level of connection between the whole diaphragm and the perimeter walls.

\subsection{Roof thrust (P6)}

There are particular roofing structural systems that exert lateral thrust and can anticipate the out-of-plane collapse mechanism of the load bearing walls supporting the roof. Some roof structural types do not exert lateral thrust simply because of their geometry or because of the addition of specific structural elements. Thrust-exerting roof types are mainly composed by rafters with no intermediate support, whose feet are fixed at a wall plate but are not properly connected among them at the ridge. Thus, rafters subjected to vertical loads push the supporting walls outwards at their top. That is why the type of roof and its ability to exert or not thrust onto the supporting walls is a key aspect regarding the seismic behavior of buildings. The level of thrust exerted by thrust-exerting roof types depends on: (a) the span covered by the roof; (b) the load of the roof; and (c) its inclination. The variation of these features inducing different levels of roof thrust was considered in the parametric study to evaluate the influence of this parameter.

\subsection{Wall openings (P7)}

The presence of openings in earthquake resistant walls mainly affects their in-plane behavior, compromising their in-plane resistance. This is particularly significant when the building is prone to suffer inplane damage, such as when sufficiently stiff diaphragms well-connected to the walls are able to avoid premature out-of-plane collapses. Damage patterns observed after earthquakes show that crack lines often follow the distribution of the façade openings, revealing the vulnerability induced by these elements. Vernacular buildings in rural areas generally present a reduced area of wall openings, but it is variable and the area of wall openings can increase significantly if the building is located in an urban environment.

\subsection{Number of floors (P8)}

With respect to the number of floors, taller buildings tend to be more vulnerable to earthquakes because the center of gravity is raised. Thus, the overturning moment of the walls due to horizontal loading also increases. This is particularly evident in unreinforced vernacular masonry buildings whose mass is mainly concentrated at the walls instead of at the floors. Vernacular buildings are typically not too high. In the rural environment, rammed earth constructions usually extend horizontally and are composed by a single story, but in the urban context they rarely present more than two stories. Stone masonry vernacular buildings in the urban context can easily present up to four stories, particularly when arranged in aggregates, such as in most European historical city centers.

\subsection{Previous structural damage (P9)}

Generally, a critical reason for the vernacular heritage to be so vulnerable to earthquakes is its advanced state of deterioration, as a result of poor maintenance or abandonment, which results in previous structural damage often going unrepaired. Existing cracks increase the vulnerability of specific parts of the structure and can anticipate its failure. The previous structural damage was simulated by imposing an initial level of damage to the structure. The numerical models were firstly loaded in one direction until reaching a certain degree of damage, and then the pushover analysis can be performed in the perpendicular direction. In this way, the initial level of damage imposed to the structure is not directly related to the resisting mechanism that will be later activated when performing the pushover analysis. In this work, the level of damage was defined following the classification proposed by Masciotta et al. [53] according to the maximum crack size: (1) slight damage, corresponding to hairline and fine cracks (with crack width $<1 \mathrm{~mm}$ ); (2) moderate damage, corresponding to a crack width between 1 and $5 \mathrm{~mm}$; and (3) severe damage, corresponding to large cracks impairing functionality (with crack width $>5 \mathrm{~mm}$ ). Taking this classification into account, a range of variation of the initial level of damage imposed was established in order to perform the parametric study.

\subsection{In-plane index (P10)}

The in-plane index ratio provides an estimation of the shear strength in each orthogonal direction and can be an indicator of the in-plan irregularity of the building. This parameter gives a measure of the inplane stiffness of the structure in each main direction and, thus, it can be considered as an indicator of the feasible seismic performance of the building [44]. For values close to 0.5 the walls are well-balanced. Values of in-plane index deviating from 0.5 show that the building has a weaker direction. The seismic capacity of a building may be jeopardized when it presents an unbalanced area of resisting walls in the two orthogonal directions. This index can be very variable in vernacular buildings, indicating very different plan configurations.

\section{Definition of seismic vulnerability classes}

The methodology adopted for the definition of the seismic vulnerability classes for the SVIVA formulation is presented. The definition of the classes for the parameter related to the maximum wall span (P2) is provided as an example of the methodology that was consistently 

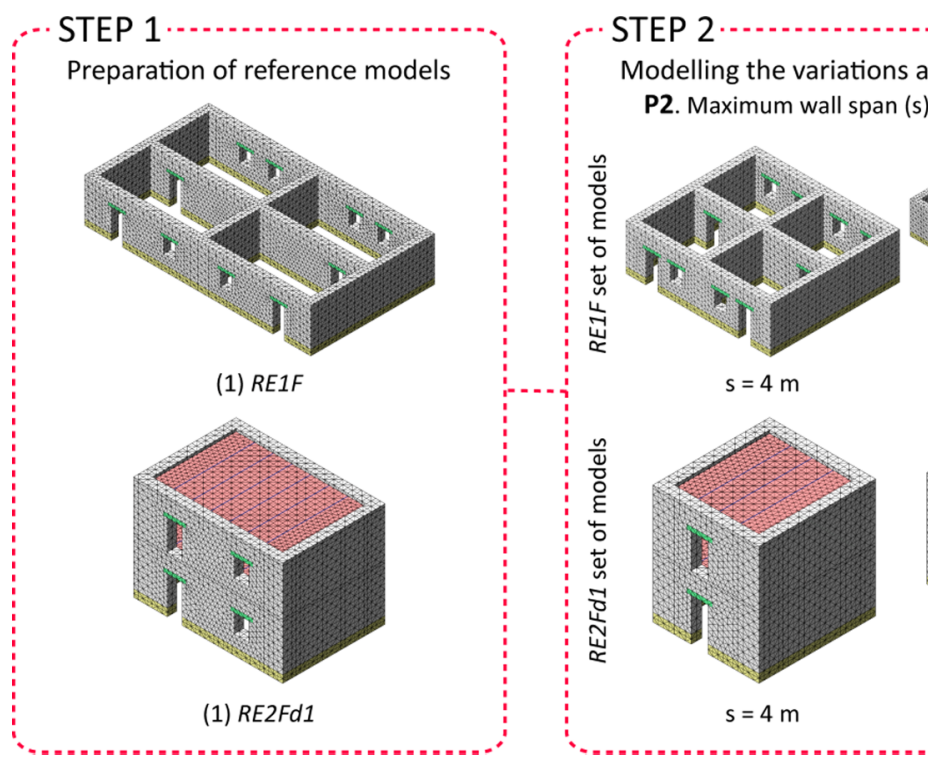

Modelling the variations according to each parameter

P2. Maximum wall span (s) - Define range of variation: $s=[4-12] \mathrm{m}$
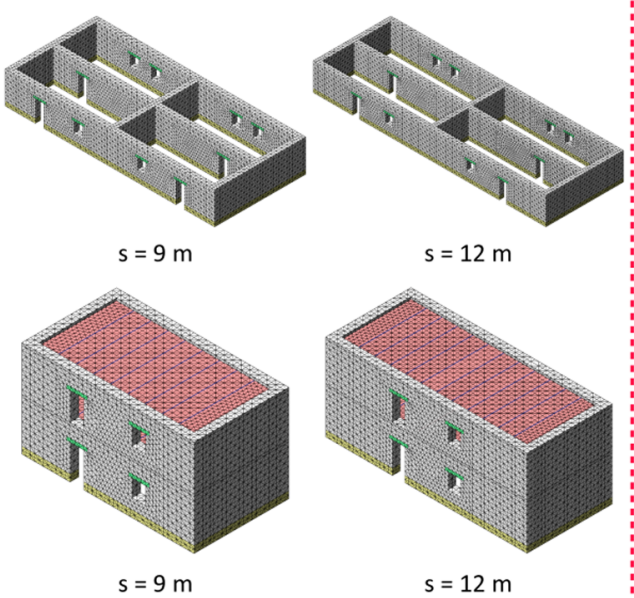

$\mathrm{s}=12 \mathrm{~m}$

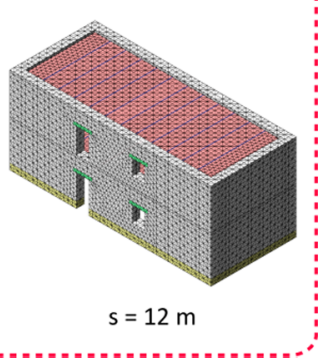

Fig. 2. Steps 1 and 2 from the methodology adopted for the definition of the seismic vulnerability classes using P2 (maximum wall span) as an example.

Table 2

Mechanical properties adopted for the different materials used in the reference models.

\begin{tabular}{llllllll}
\hline Material & $E(\mathrm{MPa})$ & $\nu$ & $f_{c}(\mathrm{MPa})$ & $G_{f c}(\mathrm{~N} / \mathrm{mm})$ & $f_{t}(\mathrm{MPa})$ & $G_{f f}(\mathrm{~N} / \mathrm{mm})$ & $\mathrm{W}\left(\mathrm{kN} / \mathrm{m}^{3}\right)$ \\
\hline Stone masonry & 1500 & 0.2 & 1.5 & 2.4 & 0.15 & 0.012 \\
Rammed earth & 300 & 0.3 & 1 & 1.6 & -1 & 0.012 & 20 \\
Timber & 10,000 & 0.2 & - & - & - & - & -12 \\
Timber diaphragms & 200 & 0.3 & - & - & - & - \\
\hline
\end{tabular}

followed for the ten key parameters. The complete process followed for the definition of the classes of the ten parameters can be found in Ortega [54].

\subsection{Step 1: preparation of reference numerical models}

The reference finite element (FE) models prepared were initially based on typical Portuguese vernacular stone masonry and rammed earth constructions, such as those shown in Fig. 1. The reference models are prepared in a generic way to easily accommodate the variations required to assess the influence of the different parameters. For the evaluation of each parameter, different reference models were prepared assuming different initial conditions and combinations of the remaining parameters. This is meant to provide a more comprehensive understanding of the influence of each parameter on buildings showing different characteristics. Fig. 2 shows the two reference models prepared for the parametric analysis aimed at defining the seismic vulnerability classes according to the maximum wall span (P2): (1) one-floor rammed earth building with flexible diaphragm $(R E 1 F)$; and (2) two-floor rammed earth building with a sufficiently rigid diaphragm well-connected to the walls able to activate their in-plane response (RE2Fd1). The use of two differentiated building typologies as reference models allows understanding the influence of the maximum wall span when the building is prone to show an out-of-plane failure mode and when is prone to present in-plane collapse mechanisms.

The software selected to perform the numerical parametric analysis was DIANA software [55]. Walls are simulated with ten-node isoparametric 3D solid tetrahedron elements (CTE30), with four-point integration scheme over the volume. The walls have at least two elements within the thickness. When modeled, the diaphragms are assumed to be composed by: (a) timber beams simulated using three-node beam elements (CL18B); and (b) cross-board sheathing modeled using six-node triangular shell elements (CT30S), aiming at simulating the in-plane deformability [52]. When modeling a proper beams-to-wall connection, the beams are considered fully embedded within the wall, going through the whole thickness. When modeling a good diaphragm-to-wall connection, the nodes at the connections between the board sheathing and the walls are assumed to share all degrees of freedom. The roof is modelled as distributed load along the walls and, when expected to exert thrust to the walls, a distributed horizontal load is also applied at the top of the walls. The displacements of the walls elements at the base are fully restrained.

Different materials are considered for the walls according to the discussion from Section 3.3. Timber is used for the lintels and floor construction elements. Only the materials used for the walls are considered to present nonlinear behavior, adopting standard isotropic Total Strain Rotating Crack Model (TSRCM). The model describes the tensile and compressive behavior of the material with one stress-strain relationship and assumes that the crack direction rotates with the principal strain axes. The tension softening function selected is exponential and the compressive function selected to model the crushing behavior is parabolic. It was selected because of its robustness and simplicity and has been already successfully applied in previous analysis of complex stone masonry and earthen structures [6,56-58]. The material properties adopted varied for the different models constructed and were based on data collected from different authors $[48,50,51,59,60]$. The particular mechanical properties adopted for the models shown in Fig. 2 are shown in Table 2 as an example.

\subsection{Step 2: preparation of the set according to the variations defined for each parameter}

On the basis of the reference model selected, the second step consists of preparing the rest of the models according to the variations defined for each parameter. A range of variation was determined for each parameter (Table 1). Thus, a set of models is prepared departing 


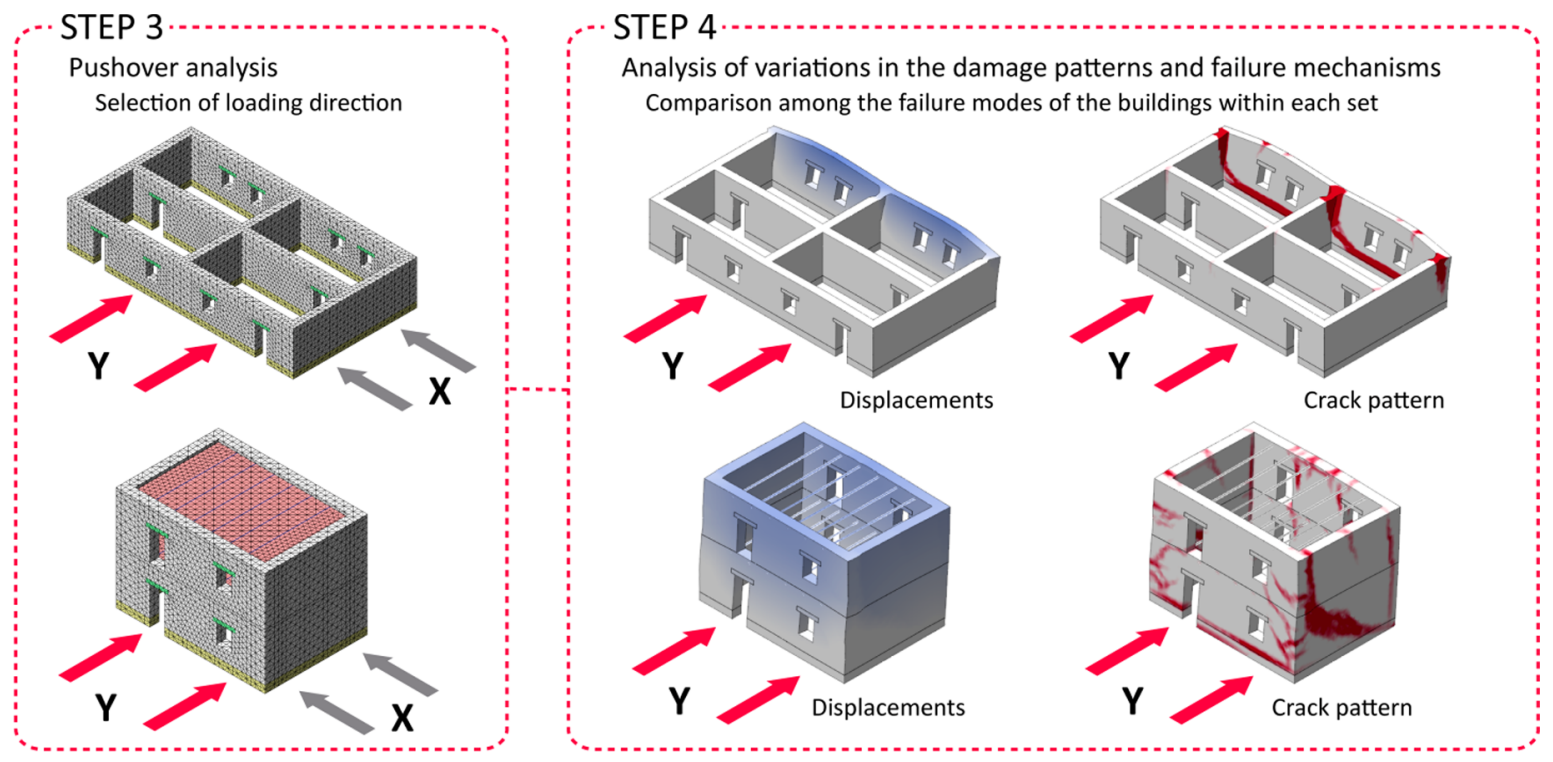

Fig. 3. Steps 3 and 4 from the methodology adopted for the definition of the seismic vulnerability classes using P2 (maximum wall span) as an example.

from each reference model according to this range, constituting the base of the parametric analysis. For example, in the same case of parameter P2, the range of maximum wall span established went from 4 to $12 \mathrm{~m}$. The maximum wall span of the reference models was $7 \mathrm{~m}$. The span was thus decreased and increased by $1 \mathrm{~m}$ until covering the whole range defined. As a result, two sets of 9 models were prepared (Fig. 2).

\subsection{Step 3: pushover analysis}

Once all the models are constructed, a pushover analysis is performed on each of them. The distribution of lateral loads in the pushover analysis was considered to be directly proportional to the mass, as generally recommended for the seismic assessment of existing masonry buildings [61]. Pushover consists of increasing the loads monotonically until reaching the collapse of the structure, which allows determining the ability of the building to resist the characteristic horizontal loading caused by the seismic action taking into account the material nonlinear behavior. Convergence was checked at each load step using the internal energy norm criteria with a tolerance of $10^{-3}$.

The direction selected to perform the pushover analyses depends on the expected response and failure mode of the buildings. Each set of models is tested in the same direction, which is commonly the one in which the buildings are assumed to be more vulnerable. However, in some cases, the models are tested in the direction in which the parameter under evaluation is supposed to have a greater influence. For example, continuing with the example above, parameter P2 evaluates the variations in the response of the building when the maximum length of a wall prone to out-of-plane movements varies. Thus, the direction selected for the pushover analyses had to be perpendicular to the walls whose span is being modified. The direction is marked in red in Fig. 3.

\subsection{Step 4: analysis of variations in the damage patterns and failure mechanisms}

This step is primarily aimed at obtaining a better understanding of the seismic behavior of vernacular buildings. The pushover analyses carried out on each model from the set allow performing a comparison among them in terms of variations in the crack patterns and failure mechanisms. This step helps to understand how the seismic response of the building changes according to the variations in the parameter under evaluation. The failure mode of each model is analyzed in terms of: (a) maximum total displacements; and (b) crack pattern; see Fig. 3.

\subsection{Step 5: building of four-linear capacity curves}

The pushover analysis allows describing the seismic response of the structure in terms of the capacity or pushover curve. The pushover curve is given as relation between the base shear coefficient or load factor (i.e. the ratio between the horizontal forces at the base and the self-weight of the structure, expressed as an acceleration in terms of $\mathrm{g}$ ) and the displacement at the control node (usually taken as the node showing the highest displacements). It should be noted that this node usually varies according to the collapse mechanism obtained, which differs between buildings. Thus, the curves are representative of the global structural behavior of the different buildings subjected to horizontal loading, not individual structural elements composing the buildings.

In order to have a common quantitative basis of comparison of the seismic capacity of the buildings, four structural limit states (LS) associated to specific damage levels exhibited by the structure are identified from the pushover curve, following recommendations available from the literature [62-64]:

LS1: Represents the onset of cracking and the end of the elastic behavior. Until this limit, the behavior of the building is essentially elastic and the structure can be considered as fully operational. The beginning of cracking is assumed to start when there is a reduction of the initial stiffness of the global response of the building up to $2 \%$. This reduction was defined after observing that the first cracks in the numerical models are visible after this reduction of the initial stiffness, characterizing the end of the elastic behavior. It is noted that the value is relatively low and is related with the low tensile strength of the materials considered in this study.

LS2: This limit state tries to depict the transition between a point where the structure is still functional and retains most of its original stiffness and strength, showing minor structural damage and cracks, and a state where significant damage is visible so that the building could not be used after without significant repair. The definition of the point depicting LS2 in the pushover curve is made by satisfying two energy criteria: (1) the first energy criterion assumes that the area below the three-linear curve formed by LS1, LS2 and LS3 coincides with the area below the pushover curve from LS1 to LS3; and (2) the second criterion assumes that the LS2 point is on the slope associated to the secant stiffness corresponding to $70 \%$ of the maximum strength.

LS3: Defined by the load factor and displacement corresponding to the attainment of the building maximum strength. The building shows 


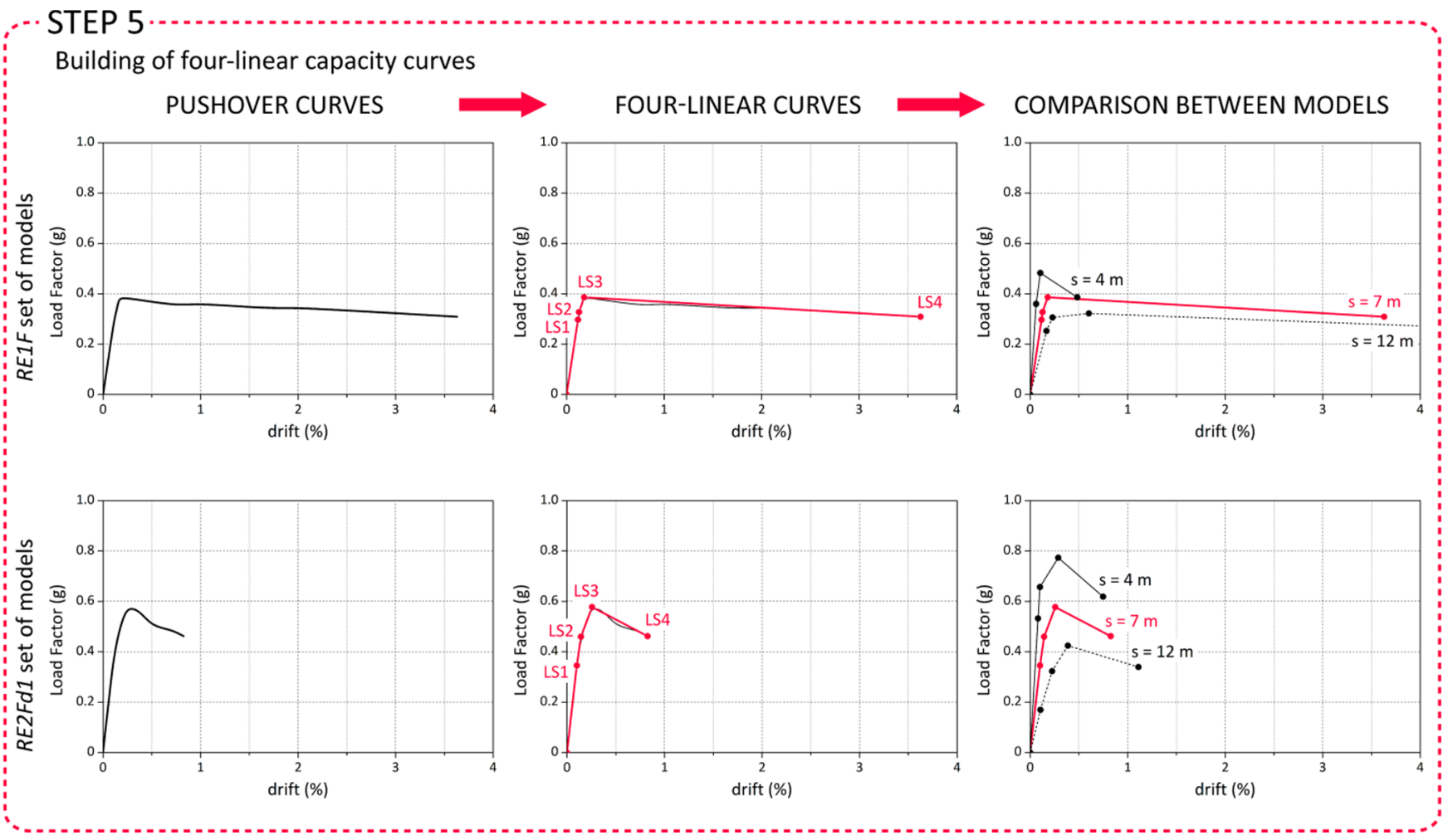

Fig. 4. Step 5 from the methodology adopted for the definition of the seismic vulnerability classes involving the transformation of the pushover curves into equivalent four-linear capacity curves, using P2 (maximum wall span) as an example.

significant structural damage and has lost a significant amount of its original stiffness. It retains some lateral strength and margin against collapse, but it cannot be used after the earthquake.

LS4: This ultimate limit state corresponds to the point where the building resistance deteriorates below an acceptable limit, which is set at the $80 \%$ of the maximum strength. Repairing the building after reaching this limit state may be neither possible nor economically reasonable. The pushover analyses were not continued after reaching this limit state.

Step 5 thus consists of transforming the pushover curves into fourlinear capacity curves according to the points associated to each LS. These four-linear capacity curves describe the seismic behavior of each building through four equivalent static horizontal loads (load factors) that the buildings can withstand before reaching each LS. Since they also provide information about the deformation capacity of the structure, they allow an easier and quantitative comparison between the structural response of the models from each set in terms of capacity, stiffness and ductility, see Fig. 4.

\subsection{Step 6: Analysis of load factor variations}

The sixth step consists of comparing the values of load factor corresponding to LS1, LS2 and LS3 for the different models within each set. LS4 is not included because it is directly determined from LS3. The load factor variations for each LS can be expressed in terms of percentage normalized by dividing the value of load factor obtained for each model of the set (i) by the maximum value of load factor obtained among the buildings analyzed:

$L S 1(\%)_{i}=\frac{L S 1(g)_{i}}{L S 1(g)_{\max }}$

$L S 2(\%)_{i}=\frac{L S 2(g)_{i}}{L S 2(g)_{\max }}$

$$
L S 3(\%)_{i}=\frac{L S 3(g)_{i}}{L S 3(g)_{\max }}
$$

Continuing with the example of P2, for both set of models, the building with $s=4 \mathrm{~m}$ showed the maximum capacity and the highest values of load factor defining LS1, LS2 and LS3. Therefore, these three values of load factor are used for the normalization of the load factors obtained for the remaining models of the set. Three curves can be constructed showing the variation of the load factor defining each LS as a function of the wall span, see Fig. 5. The curves show in a clear manner the influence of the parameters in the global seismic behavior of the buildings.

\subsection{Step 7: definition of seismic vulnerability classes}

The seismic vulnerability classes are defined according to the variation of the load factor corresponding to the attainment of the maximum capacity of the building (LS3). The criterion followed for the definition of the typical four classes of increasing vulnerability (A, B, C and D) consists of dividing equally the total range of variation $\left(L S 3(\%)_{\max }-L S 3(\%)_{\min }\right.$ ) within each set into four parts. Each interval is associated with a vulnerability class and the buildings are classified according to the interval they lie within. Fig. 6 illustrates this process using as an example the definition of the classes for the seismic vulnerability parameter P2. It is noted that the ranges of variation obtained for each set can differ, resulting in differences in the definition of the seismic vulnerability classes. As an example, in the definition of the classes for P2, within the RE1F set of models, the building with $s=5 \mathrm{~m}$ classifies as A, whereas within the RE2Fd1 set of models, the building with $s=5 \mathrm{~m}$ classifies as B. The final classification is made taking into account these discrepancies by adopting the most unfavorable class, in order to be on the safe side. Thus, buildings with $s=5 \mathrm{~m}$ are considered as class $\mathrm{B}$. 


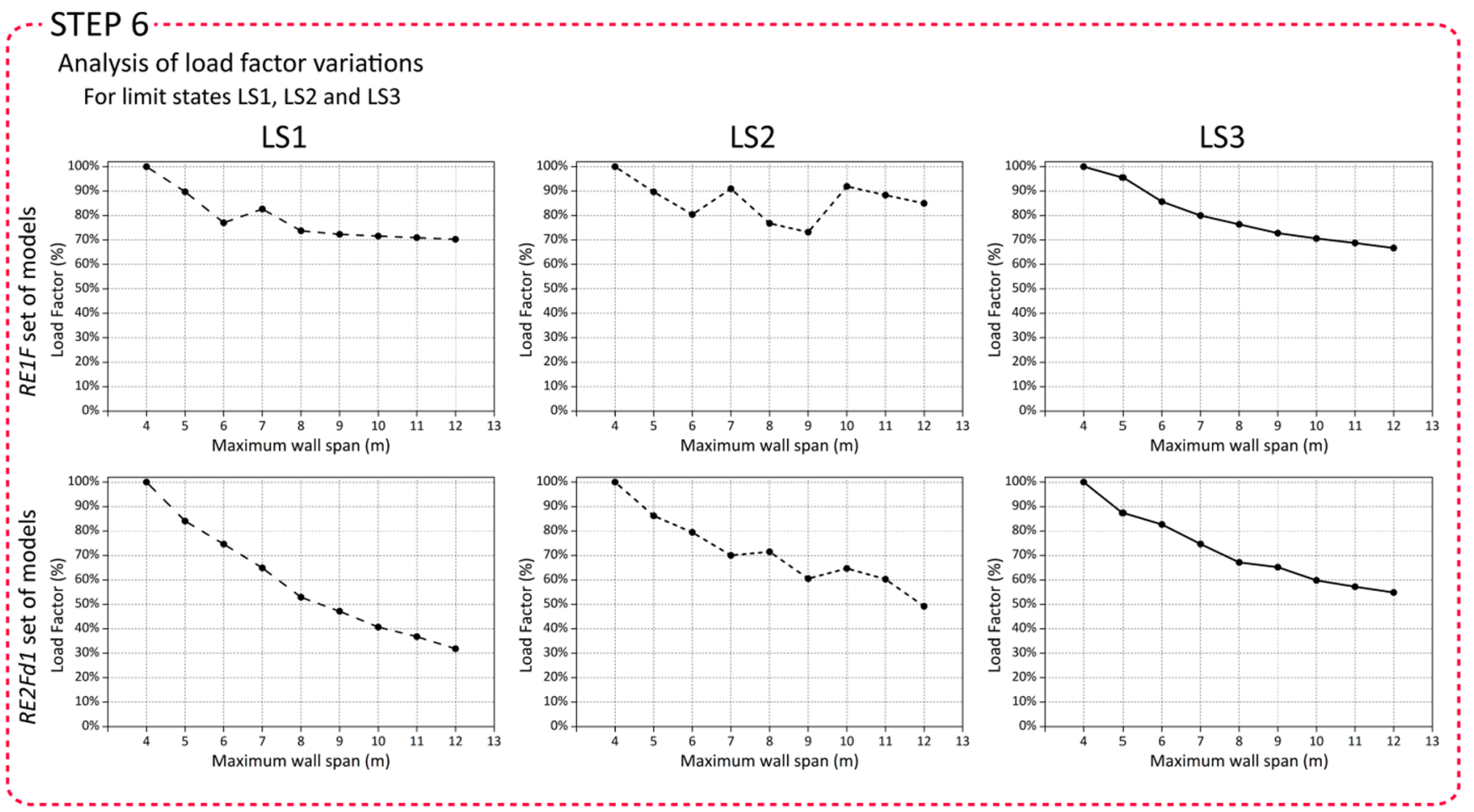

Fig. 5. Step 6 from the methodology adopted for the definition of the seismic vulnerability classes that analyzes the variation of the load factors defining each LS according to the variations in the parameters, using P2 (maximum wall span) as an example.

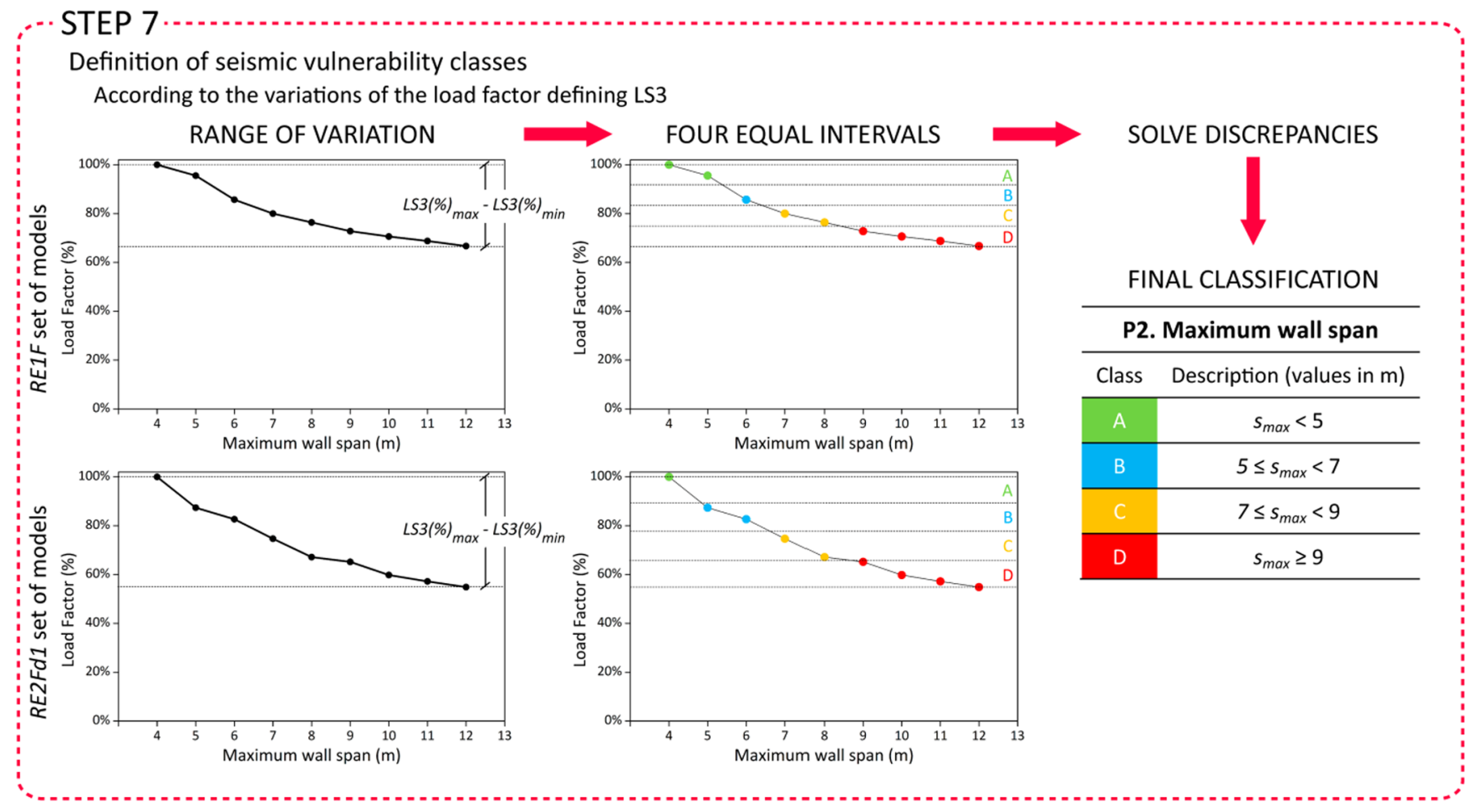

Fig. 6. Final step 7 from the methodology adopted for the definition of the seismic vulnerability classes using P2 (maximum wall span) as an example.

\subsection{Summary}

The extensive numerical parametric study included the preparation of 277 numerical models and concluded with the definition of the seismic vulnerability classes for the ten key parameters. The study helped also to validate that the selected parameters are influential in the seismic behavior of vernacular buildings. The seismic vulnerability classes defined for each parameter are shown in Table A1 in Appendix A. It provides: (1) quantitative ranges of values delimiting each parameter class, whenever possible; and (2) qualitative description of the classes intended to serve as a reference when doing the assessment in terms of simple visual inspections. 


\section{Definition of seismic vulnerability assessment parameters weight}

As previously mentioned, the vulnerability index $\left(I_{v}\right)$ is calculated as the weighted sum of the seismic vulnerability assessment parameters. The weights $\left(p_{i}\right)$ are the coefficients that multiply the vulnerability class numeric value $\left(C_{v i}\right)$ and, therefore, indicate the relative importance of each parameter in estimating the overall building seismic vulnerability. Parameters weights have been commonly assigned based on expert opinion. The present work proposes to specify the weights that are necessary to complete the SVIVA formulation following two different approaches: (1) statistical analysis; and (2) expert judgment.

\subsection{Definition of the parameters weight based on statistical analysis}

The pushover parametric study performed to obtain the seismic vulnerability classes required the construction of 277 numerical models with varying geometrical, construction, material and structural characteristics. Since most models were analyzed in the two orthogonal directions, more than 400 pushover analyses were finally performed. The results of the numerical study were organized within a database. Multiple linear regression (MR) analysis was applied to analyze the database, which has a large number of variables and complex and unclear relationships among them. The use of MR is ultimately intended to investigate if the parameters are able to predict the seismic response of buildings, in terms of the load factor associated to LS3, which was chosen because it was considered as the most determining when evaluating the seismic behavior of buildings. It represents the attainment of the maximum capacity of the building and has a very clear physical meaning.

Regression analysis is a popular statistical method used to investigate the dependence of one output variable on one or more other input variables. In the present case, the ten parameter variables related to the ten key seismic vulnerability assessment parameters were the input variables, while LS3 was the output variable. The objective was to define and quantify the relationship among them through a mathematical model. A multiple regression model is required because there are several input variables. The relationship between variables is often very complex and the simplest approach consists of fitting a multilinear equation to the data, which reads:

$Y=\beta_{0}+\beta_{1} x_{1}+\beta_{2} x_{2}+\cdots+\beta_{k} x_{k}+\varepsilon$

where $Y$ is the output variable and $k$ is the number of input explanatory variables $\left(x_{k}\right)$. The parameters $\beta_{k}$ are called the regression coefficients and $\varepsilon$ is the error. The line defined by the regression equation (Eq. (6)) describes how the response changes according to the explanatory variables. Each regression coefficient is a slope of the line and represents the expected change in the response per unit change in the input variable, when the remaining variables are held constant. For this reason, since they provide a measure of the amount of change, they can be used to compare the relative strength of the various predictor variables in the prediction of the dependent variable. This information precisely contributes to understand which parameters are more influential on determining the seismic vulnerability of vernacular buildings, which allows sorting the ten parameters by importance. Weights can thus be attributed to each parameter according to this arrangement, which enables their numerical definition. Fig. 7 summarizes the steps followed for parameters weights definition.

\subsubsection{Data analysis and extension of the database}

The first step for the definition of the parameters weights $\left(p_{i}\right)$ for the SVIVA formulation dealt with the organization of the database. Thus, data was structured in a database composed of 11 attributes. After the definition of the seismic vulnerability classes for the ten parameters, each model could be defined in terms of the class assigned to each parameter. Since there are only four classes of increasing seismic vulnerability, the ten input variables associated to the parameters are accordingly expressed in a discrete form, assuming only four countable numbers from 1 to 4 , associated to the classes A to D, respectively. On the other hand, the output variable (the load factor defining LS3) is expressed as a continuous variable expressed in $g$, whose value typically ranges from 0 to 1 .

After a preliminary data analysis performed, the extension of the database was not deemed enough to define a robust regression model

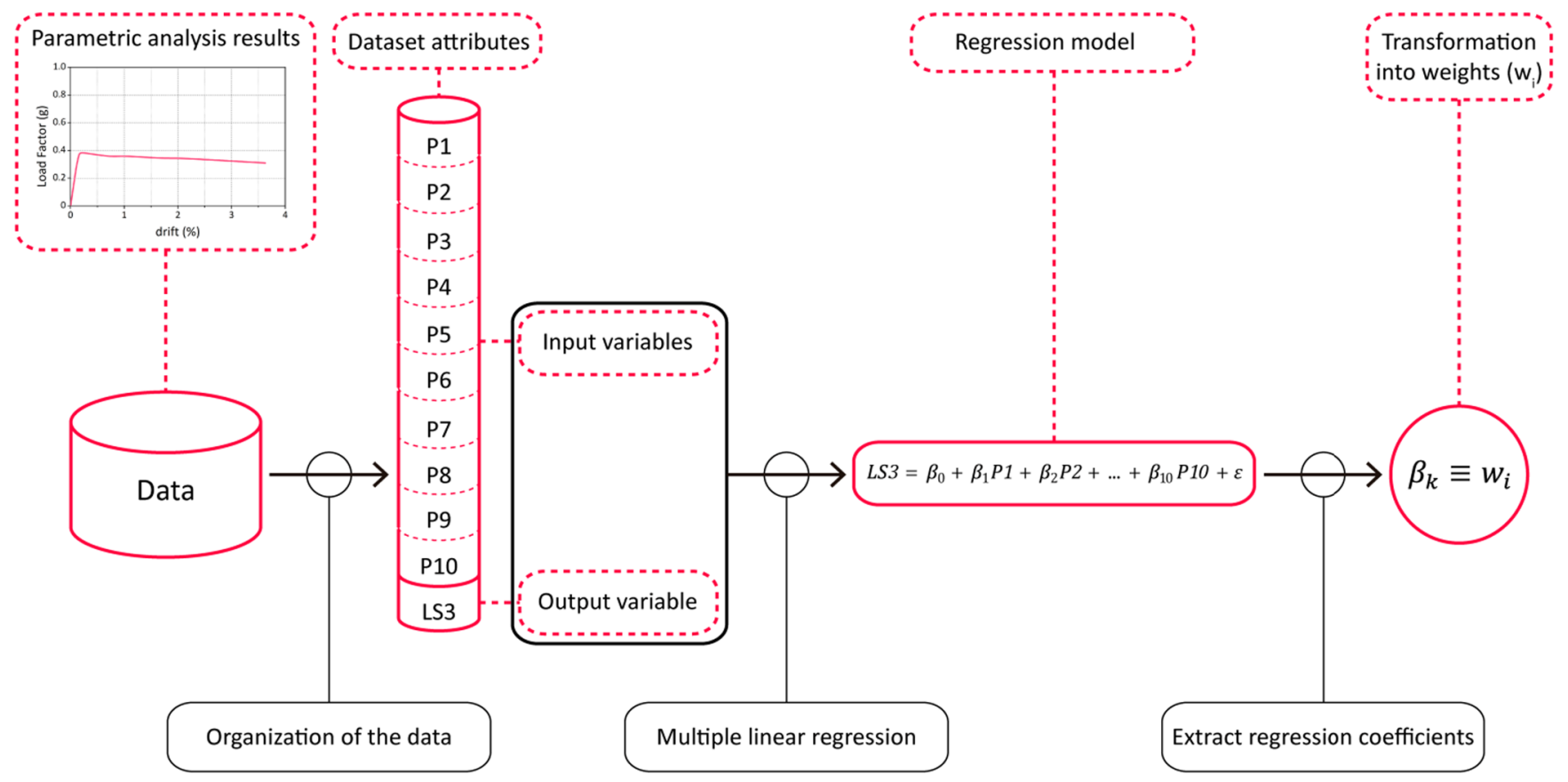

Fig. 7. Methodology adopted for the definition of the seismic vulnerability assessment parameters weights. 
Table 3

Statistical measures of the variables.

\begin{tabular}{|c|c|c|c|c|c|c|c|c|}
\hline Variables & & Minimum & Maximum & Mean & Median & Mode & STD & Skewness \\
\hline \multirow[t]{10}{*}{ Input } & $\mathrm{P} 1$ & 1 & 4 & 1.59 & 1 & 1 & 0.95 & 1.48 \\
\hline & P2 & 1 & 4 & 2.1 & 2 & 1 & 1.06 & 0.17 \\
\hline & P3 & 1 & 4 & 3.36 & 4 & 4 & 1.04 & -1.25 \\
\hline & P4 & 1 & 4 & 1.44 & 1 & 1 & 0.94 & 1.90 \\
\hline & P5 & 1 & 4 & 2.71 & 3 & 4 & 1.38 & -0.27 \\
\hline & P6 & 1 & 4 & 1.24 & 1 & 1 & 0.70 & 3.04 \\
\hline & P7 & 1 & 4 & 1.64 & 1 & 1 & 1.04 & 1.29 \\
\hline & P8 & 1 & 4 & 2.39 & 3 & 1 & 1.21 & -0.09 \\
\hline & P9 & 1 & 4 & 1.29 & 1 & 1 & 0.77 & 2.65 \\
\hline & P10 & 1 & 4 & 2.68 & 3 & 2 & 0.97 & -0.08 \\
\hline Output & LS3 $(g)$ & 0.03 & 1.24 & 0.42 & 0.41 & 0.41 & 0.21 & 0.62 \\
\hline
\end{tabular}

that allows a confident estimation of the parameters weights. Considering the pattern of variability within each parameter variable (i.e. the distribution of buildings belonging to each class), a lack of balance (or asymmetry) was detected. Due to the use of reference models showing similar initial conditions for the definition of the classes, some seismic vulnerability classes in certain parameters are more frequent than others. For example, in the case of parameter related to the wall slenderness (P1), the height and the thickness of the walls of most of the models constructed did not vary when assessing other parameters and most buildings from the database belong to class A.

Therefore, additional numerical models were built in order to enlarge the database. The main criterion applied for the enlargement of the database was to ensure that there are a minimum of 25 models representing each parameter class, in order to contain a meaningful statistical amount for all of them. The new models were then prepared by randomly combining the parameters classes. In total, 30 numerical models were prepared and 112 analyses were performed on the new set of models prepared for the enlargement of the database. The precise information on the process of extension of the database is detailed in Ortega [54]. This led to a final database composed of 530 results obtained from pushover analyses performed on the FE models. Despite the limitations of the database, which certainly cannot cover all possible cases, it is considered to be sufficiently representative.

Table 3 provides a deeper insight into the data by showing some statistical measures of the variables. It is noted that there is still an asymmetry in the distribution of the data in most parameters, despite the additional models constructed. Nevertheless, an asymmetry was expected since some classes are more typical than others in vernacular constructions. Thus, continuing with the previously mentioned parameter P1 shows a clearly skewed distribution towards lower values of wall slenderness. The vast majority of the values lie within class A and $\mathrm{B}$, which implies values of slenderness $\lambda<9$. This is reasonable given that vernacular buildings rarely present values of wall slenderness greater than 9 .

\subsubsection{Multiple regression analysis for the definition of vulnerability index} weights

The multiple regression analysis was performed using $\mathrm{R}$ software [65]. The multiple linear regression model (MRO) obtained measures the capacity of the ten parameters variables to predict LS3 adopting the simplest function as the structure:

MR0: $L S 3 P 1+P 2+P 3+P 4+P 5+P 6+P 7+P 8+P 9+P 10$

which leads to the following regression equation:

$$
\begin{aligned}
L S 3= & 1.681-0.058 \times P 1-0.017 \times P 2-0.087 \times P 3-0.04 \\
& \times P 4-0.096 \times P 5-0.032 \times P 6-0.088 \times P 7-0.093 \\
& \times P 8-0.042 \times P 9-0.026 \times P 10
\end{aligned}
$$

Fig. 8 illustrates the predicted versus observed LS3 values. All values are close to the $45^{\circ}$ line and most of them lie within the $45^{\circ} \pm 0.1 \mathrm{~g}$

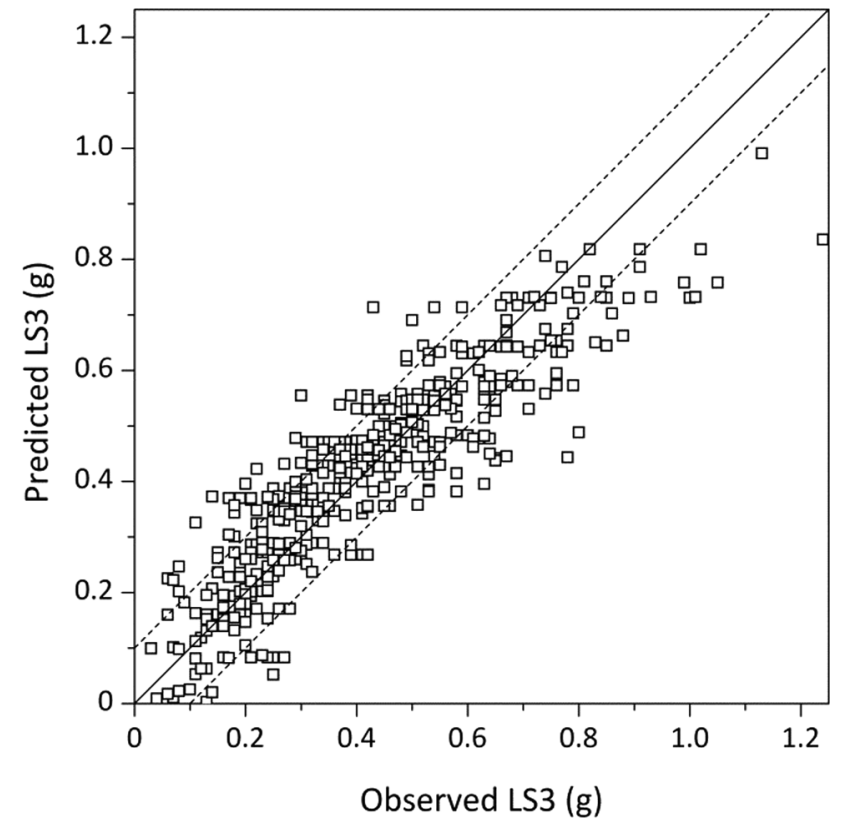

Fig. 8. Predicted versus observed LS3 values for the regression model MRO.

lines. This indicates that the error between the predicted and the observed value obtained is lower than $0.1 \mathrm{~g}$ for most cases. The behavior of the model is deemed very satisfactory, considering that the model predicts quite accurately the maximum capacity of the building using as input merely the parameters classes.

The performance of the model can be measured in terms of errors and coefficient of determination $\left(R^{2}\right)$. The errors relate to the difference between the predicted LS3 and the numerical (observed) LS3. The maximum error observed $\left(\varepsilon_{\max }\right)$ is $0.405 \mathrm{~g}$, which is large, but the Mean Absolute Error (MAE) and the Root-Mean-Squared Error (RMSE) are $0.075 \mathrm{~g}$ and $0.095 \mathrm{~g}$ respectively, being both of them below $0.1 \mathrm{~g}$, which

Table 4

Regression coefficients from MRO model in absolute value and parameters weight definition.

\begin{tabular}{llll}
\hline & $\beta$ & $|\beta|$ & Vulnerability index weight $\left(p_{i}\right)$ \\
\hline P1 & 0.058 & 0.100 & 1.00 \\
P2 & 0.017 & 0.029 & 0.50 \\
P3 & 0.087 & 0.150 & 1.50 \\
P4 & 0.040 & 0.070 & 0.75 \\
P5 & 0.096 & 0.165 & 1.50 \\
P6 & 0.032 & 0.056 & 0.50 \\
P7 & 0.088 & 0.152 & 1.50 \\
P8 & 0.093 & 0.160 & 1.50 \\
P9 & 0.042 & 0.072 & 0.75 \\
P10 & 0.026 & 0.045 & 0.50 \\
\hline
\end{tabular}




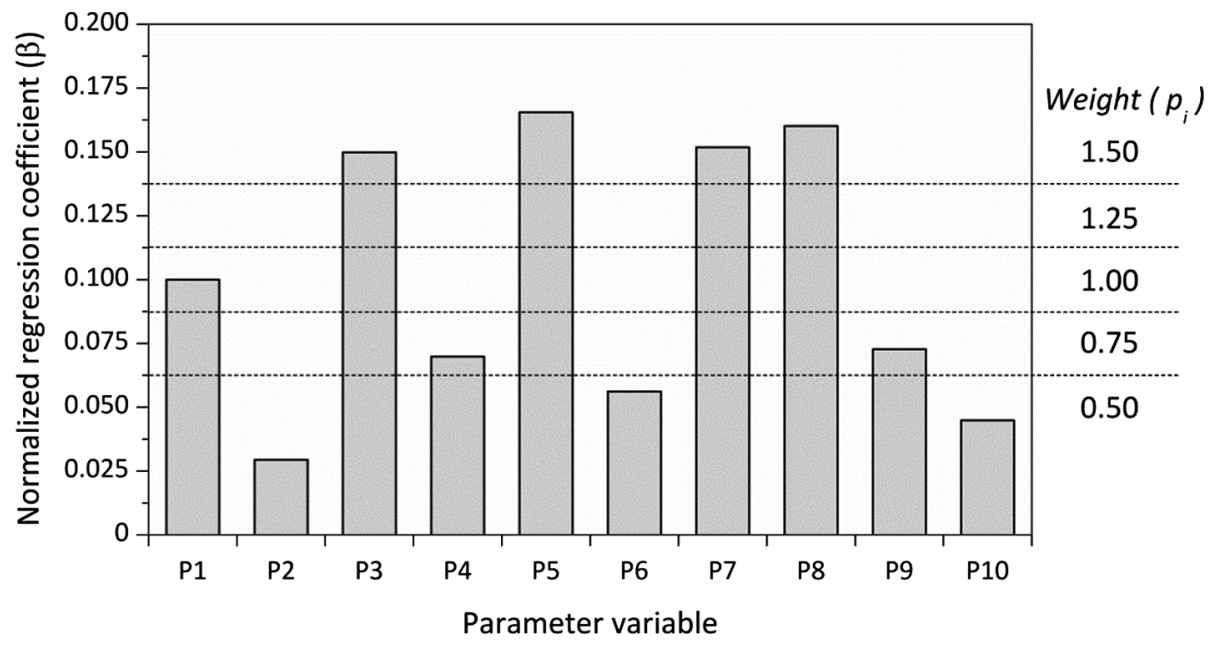

Fig. 9. Vulnerability index parameters definition using normalized regression coefficients $(|\beta|)$.

can be considered small. The coefficient of determination, $R^{2}$, is 0.772 and measures how well the model fits the actual data. It is noted that $R^{2}$ here refers to the adjusted R-squared. The performance of the model in terms of adjusted $R^{2}$ is deemed satisfactory $\left(R^{2}=0.772\right)$.

The results from the regression analysis confirmed the ability of the multiple regression equation to estimate LS3. Subsequently, the ten key parameters selected are confirmed to be relevant predictors of the maximum seismic capacity of the building. Thus, the regression equation (Eq. (8)) could be used for the estimation of the parameters weights through the regression coefficients $\left(\beta_{k}\right)$. It is worth highlighting that all coefficients are negative because an increase in the seismic vulnerability parameter class leads to a decrease in the output variable. In this case, understanding a unit increase in a predictor is straightforward because it directly corresponds to an increase in the vulnerability class, and all of the predictors are defined within the same range of classes, from 1 to 4 . For example, a unit increase in the seismic vulnerability class of P1 leads to a decrease in the maximum capacity of the building of $0.058 \mathrm{~g}$, but a unit increase in the class of P5 leads to a decrease in LS3 of $0.096 \mathrm{~g}$, which is almost the double (Eq. (8)). The higher the absolute values of the regression coefficient of a specific parameter, the stronger its influence in determining LS3.

Table 4 compiles the absolute values of the regression coefficients obtained. The table also shows the normalized absolute values $(|\beta|)$ so that they all sum to unity, which are used for the numerical definition of the parameters weights. Vulnerability index methods available in the literature $[21,23,33,36,66]$ typically use weights for the parameters ranging from 0.25 to 1.50 in 0.25 intervals. Therefore, the criterion followed for the definition of the weights consisted of approximating the normalized regression coefficients to multiples of 0.025 establishing 0.050 and 0.150 as minimum and maximum respectively. Five ranges could be defined, directly associated to different weights: (a) $|\beta|<0.0625 \equiv p_{i}=0.50 ; \quad$ (b) $0.0625<|\beta|<0.0875 \equiv p_{i}=0.75$; $0.0875<|\beta|<0.1125 \equiv p_{i}=1.00$; (d) $0.1125<|\beta|<0.1375 \equiv p_{i}=1.25$; and (e) $|\beta|>0.1375 \equiv p_{i}=1.50$. The final weights are also displayed in Table 4. Fig. 9 shows the graphical representation of the coefficients for a better visualization of their relative importance and the criterion used for the definition of the weights.

\subsection{Definition of the parameters weight based on expert opinion}

As aforementioned, besides the analytical procedure, the present paper also introduces the expert point of view into the understanding and definition of the parameters weight for the SVIVA formulation. The expert opinion was collected through a survey questionnaire carefully prepared. However, there is always a challenge in transforming subjective data and opinions expressed in terms of preferences and comparisons into quantitative results that can be used for the numerical definition of the parameters weight. The questionnaire was prepared in order to be later processed using the Analytical Hierarchy Process (AHP) proposed by Saaty [67]. It has been employed for similar studies in other fields of civil engineering that required the definition of parameters weights based on expert judgment $[68,69]$.

\subsubsection{Questionnaire survey and analytical Hierarchy process (AHP) methodology}

The questionnaire survey was prepared using the Google Forms digital platform. The survey was web based, which facilitated the distribution among experts throughout the world. The AHP is based on establishing pairwise comparisons among the parameters under evaluation in order to judge their relative importance in pairs. Thus, the survey asks the respondents to compare the relative importance of the parameters in a scale from 1 to 9 , according to the fundamental scale defined by the AHP [67]. In this scale, 1 means that the factors under comparison have equal importance, while 9 means that one factor is extremely more important than the other. Thus, a question of the survey was composed of two parts: (1) a pairwise comparison intended to indicate which parameter is more important, if any; and (2) a rating scale to compare the relative importance of the two parameters according to the AHP scale. An example of the questions reads like:

(1) Please, indicate which of the following parameters you consider has a greater influence on the seismic behavior of vernacular buildings: o TYPE OF MATERIAL: Type of material used for the structural elements (load bearing walls) of the building (e.g. rammed earth, irregular stone masonry, dressed stone masonry, etc.)

o HORIZONTAL DIAPHRAGMS: Type of horizontal diaphragm (floors and roofs) and its connection to the load bearing walls o Equal importance

(2) Compare their relative importance in the provided scale from 1 to 9:

\begin{tabular}{ccccccccccc}
\hline & 1 & 2 & 3 & 4 & 5 & 6 & 7 & 8 & 9 & \\
$\begin{array}{c}\text { Equal impor- } \\
\text { tance }\end{array}$ & 0 & 0 & 0 & 0 & 0 & 0 & 0 & 0 & 0 & $\begin{array}{c}\text { Extreme importance of one } \\
\text { parameter over the other }\end{array}$ \\
\hline
\end{tabular}

Two different surveys were prepared with a different set of 25 questions 


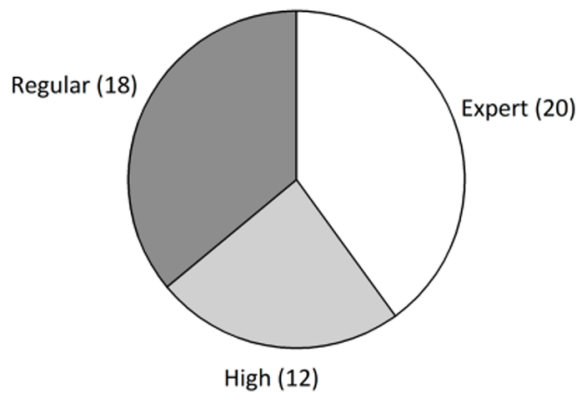

(a)

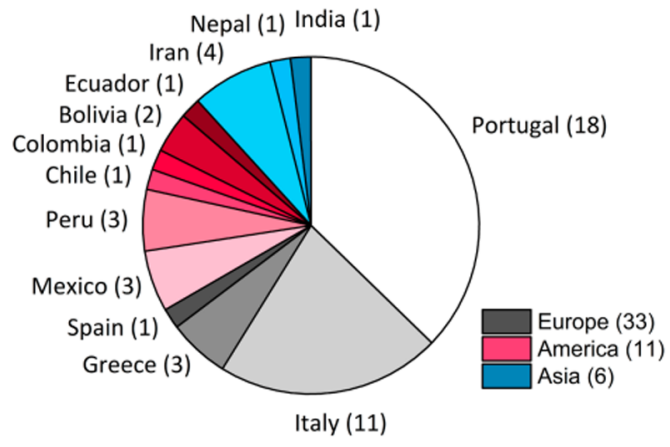

(b)

Fig. 10. Respondents profile in terms of: (a) assumed expertise according to academic status; and (b) country of origin.

in each other, which were deemed enough to apply the AHP, which requires certain amount of redundancy in the answers. The objective of using the AHP was to generate a pairwise comparison matrix of order $n$ (where $n$ is the number of parameters), from which the parameters can be arranged hierarchically in terms of importance for the definition of the weights. Since the matrix is reciprocal and the value of importance assigned to one parameter $i$ when compared with parameter $j$ is the reciprocal value assigned to $j$ when compared with $i$ (i.e. $a_{j i}=1 / a_{i j}$ ), the number of judgments required is $n(n-1) / 2$. This would result in preparing 45 questions to consider the 10 parameters. However, the number of questions was reduced in order to avoid that the survey becomes repetitive. The problems of the incompleteness of the matrix could be tackled based on the method proposed by Harker [70], which allows completing the matrix and thus deriving the weights without the need of including the complete set of pairwise comparisons in the survey.

The survey was distributed and collected from a total of 50 experts working in the field of seismic engineering and historical and vernacular masonry structures. The experts mainly belong to the academic environment, including professors, post-doctoral researchers, Ph.D and master's degree students. They were grouped in three categories based on the assumed level of knowledge in the field: expert, high and regular knowledge. Professors and post-doctoral researchers were considered to have expert knowledge, Ph.D researchers were classified as high knowledge and the master's degree students as regular knowledge (Fig. 10a). A particular emphasis was also placed on distributing the survey among specialists from seismic prone regions all over the world, so that the particularities of the seismic behavior of vernacular constructions from different areas of the world are indirectly included within the survey. Experts from countries such as Italy, Greece, Mexico, Peru, Iran, and Nepal were surveyed (Fig. 10b).

\subsubsection{Definition of the weights}

Following the AHP, the weights were derived using the eigenvector method. This method establishes that the attribute weights are equal to the components of the normalized principal eigenvector of the pairwise comparison matrix resulting from the survey. Thus, for each respondent of the survey, a matrix was composed using the answers provided and completing the missing elements of the matrix with the abovementioned method proposed by Harker [70]. From each matrix A, the principal eigenvector $(w)$ can be computed as:

$A w=\lambda_{\max } w$

where $\lambda_{\max }$ is the largest or principal eigenvalue of $A$. The principal eigenvector ( $w$ ) obtained using Eq. (9) is then normalized. Finally, according to the AHP the components of the normalized principal eigenvector $(\widehat{w})$ can be directly associated with the parameters weights $\left(p_{i}\right)$ :

$\widehat{w}_{i, 1}=p_{i}$

This procedure was followed for the total of 50 answers collected, calculating the vector of relative weights for each answer. Table 5

Table 5

Relative weights considering the mean values from all answers.

\begin{tabular}{|c|c|c|c|c|c|c|c|c|c|c|c|c|c|c|c|}
\hline & $\widehat{w}_{\text {mean }}$ & $\sigma$ & C.o.V. & & & & & & & & & & & & \\
\hline P1 & 0.113 & 0.061 & $53.96 \%$ & & 0.20 & & & & & & & & & & \\
\hline P2 & 0.076 & 0.046 & $59.97 \%$ & & 0.18 & & & & & & & & & & \\
\hline P3 & 0.087 & 0.085 & $97.44 \%$ & & 0.18 & & & & & & & & & & \\
\hline P4 & 0.153 & 0.079 & $51.45 \%$ & & $0.16-$ & & & & & & & & & & \\
\hline P5 & 0.128 & 0.073 & $57.43 \%$ & & 0.14 & & & & & & & & & & \\
\hline P6 & 0.059 & 0.045 & $77.11 \%$ & \pm & & & & & & & & & & & \\
\hline P7 & 0.069 & 0.050 & $72.64 \%$ & $\frac{1}{00}$ & 0.12 & & & & & & & & & & \\
\hline P8 & 0.122 & 0.096 & $78.87 \%$ & 3 & 0.10 & & & & & & & & & & \\
\hline P9 & 0.101 & 0.081 & $80.03 \%$ & $\stackrel{0}{\geq}$ & 0.08 & & & & & & & & & & \\
\hline \multirow[t]{3}{*}{ P10 } & 0.092 & 0.064 & $70.21 \%$ & $\frac{\pi}{2}$ & 0.06 & & & & & & & & & & \\
\hline & & & & & & P1 & P2 & P3 & P4 & P5 & P6 & P7 & P8 & P9 & P10 \\
\hline & & & & & \multicolumn{11}{|c|}{ Parameter variable } \\
\hline
\end{tabular}




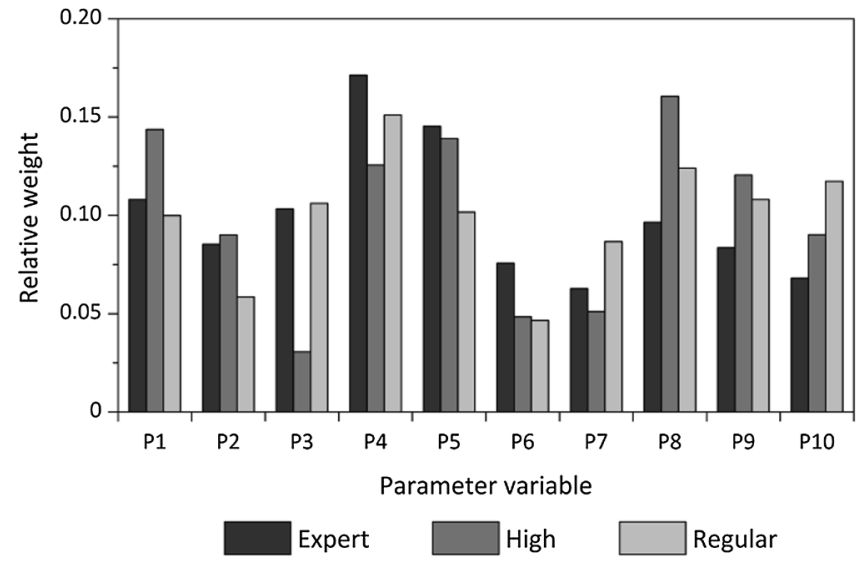

(a)

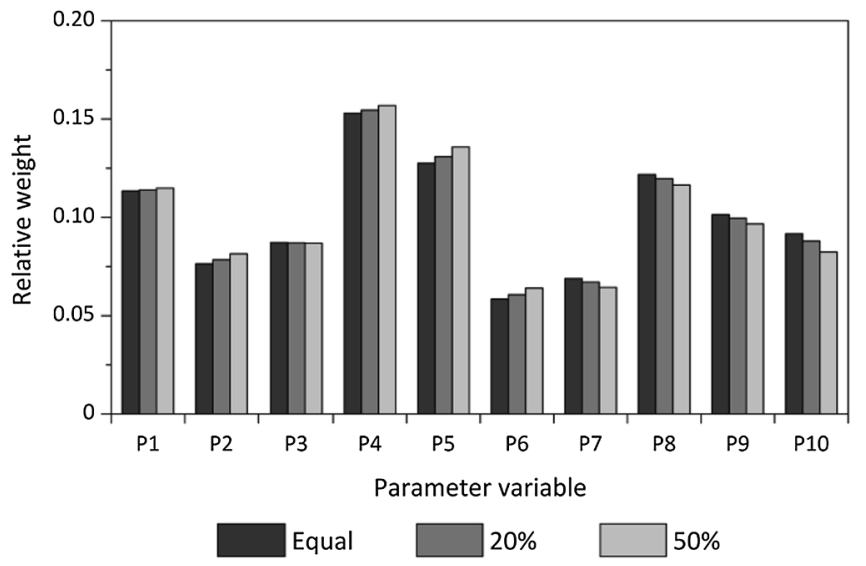

(b)

Fig. 11. (a) Parameters weights according to the assumed level of knowledge of the respondents; and (b) different scenarios considered for the definition of the weights taking into account the levels of knowledge.

shows the mean value of the relative weights obtained from all the answers. There is a great variety in the results, as shown by the standard deviation $(\sigma)$ and coefficient of variation (C.o.V.), which reaches values close to 1 for some parameters (such as P3). This depicts a wide discrepancy among the experts in identifying the most influential parameters and thus emphasizes the difficulty in assigning the weights based solely on empirical observations.

Fig. 11a presents the mean values of the parameters weights calculated independently for each level of knowledge assumed for the respondents, namely expert, high and regular. There are differences between the weights assigned by experts with different level of knowledge but, with the exception of P3, the relative difference among the parameters weights is similar for the three levels of knowledge. The weights shown in Table 5 were calculated assuming the same importance in the answers for the different levels of knowledge. However, in order to refine the definition of the weights taking into account the assumed level of knowledge of the respondents, two different scenarios were additionally considered and shown in Fig. 11b: (1) increase in $20 \%$ the importance of the answers from the Expert level and decrease in the same proportion the importance of the answers obtained from the Regular level respondents; and (2) the same as in the previous case but considering a 50\% variation between the knowledge levels. The comparison of the results shows that there are not significant differences among them.

According to the opinion of experts, the parameters that are more relevant on the seismic behavior of vernacular buildings are: P1 (wall slenderness), P4 (wall-to-wall connections), P5 (horizontal diaphragms) and P8 (number of floors). Fig. 12 shows the frequency of the different parameters to be selected by the different respondents as the most and the least influential. This confirms that the majority of the respondents understand that the connection between perpendicular walls, the type of horizontal diaphragms and the number of floors are crucial in defining the seismic behavior of a building. It is worth highlighting that the type of material is considered by the majority of the respondents to be the least influential parameter in the seismic behavior, while around $10 \%$ consider this parameter to be the most important. This is in agreement with the great variability shown in Table 5 , recognizing a notable lack of consensus over the influence of this parameter. There is a quite uniform understanding that the maximum wall span (P2), the roof thrust (P6) and wall openings (P7) are among the least influential parameters.

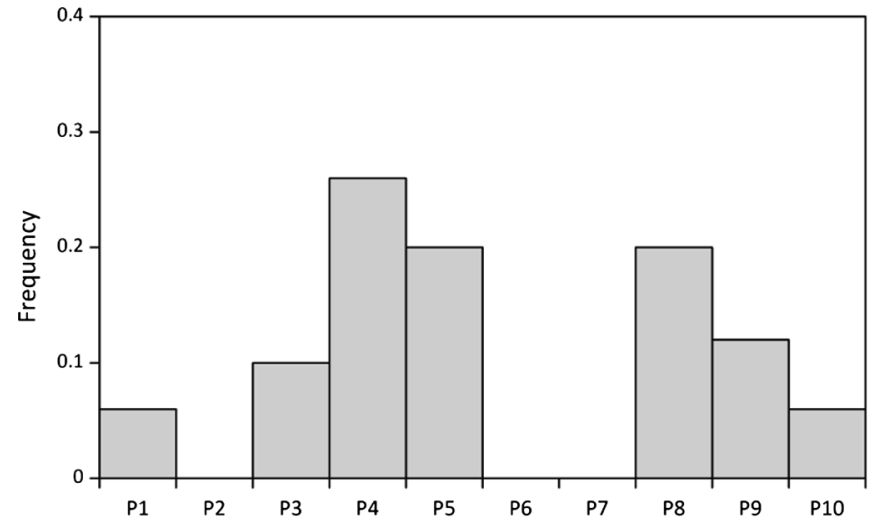

(a) Parameters selected as most influential

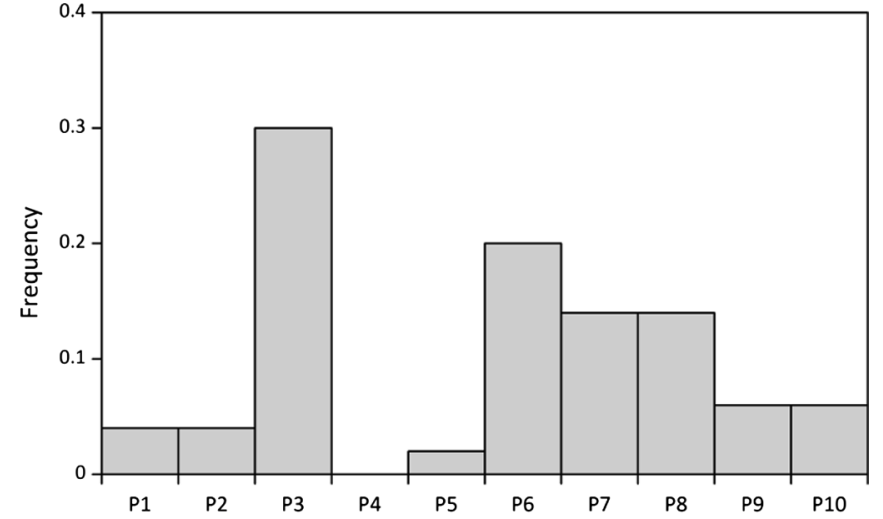

(b) Parameters selected as least influential

Fig. 12. Frequency of the parameters being selected as: (a) the most; and (b) the least influential. 


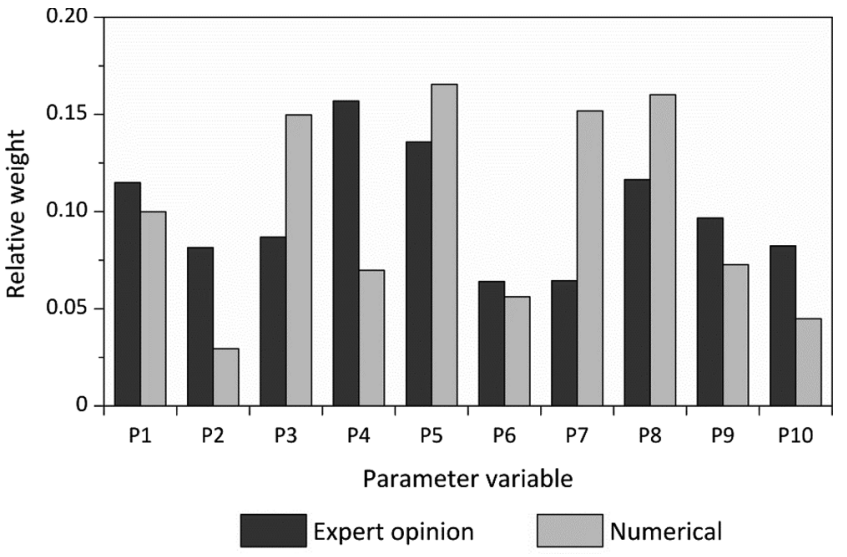

Fig. 13. Comparison among the relative weights calculated based on expert opinion and numerically.

\subsection{Comparison between the statistical and expert-based approaches}

Despite the variations in the answers to the questionnaire, results show consistency and are relevant, providing a good insight of the expert opinion on this matter. Nevertheless, there are important differences with the results obtained from the numerical analysis. Fig. 13 shows a comparison among: (a) the weights obtained from the statistical approach (Table 4); and (b) the weights calculated based on expert judgment, finally established considering the scenario where the importance of the answers from the respondents assumed to have an expert level of knowledge is increased 50\% (Fig. 11b).

Both experts and numerical results led to overall similar weights for some parameters. For example, P5 is considered among the most influential parameters. The weights obtained for P1, P6, P8 and P9 are also well-matched. However, there is a remarkable difference for other parameters. For example, the type of material (P3) and the wall openings (P7) have a significant influence according to the numerical results, while the survey respondents did not give them such an importance. In the case of the type of material, the discrepancy among the experts has already been discussed. Regarding wall openings, the difference may lie in the fact that the classes defined in the numerical results take into account the effect of wall openings when the building presents rigid diaphragms that activate the in-plane response of the walls, which is the scenario for which this parameter has a greater influence. Vernacular constructions many times lack this positive diaphragm effect and seismic behavior mainly depends on the out-of-plane resistance of the walls, on which the area of wall openings has a minimum influence [54]. Post-earthquake damage observations showing out-of-plane collapses may lead to the assumption that wall openings have a smaller influence. On the other hand, most experts judged as critical the importance of the connection among orthogonal walls (P4), whereas the numerical results granted it a more moderate influence in comparison with other parameters. This difference is possibly due to the fact that a bad connection leading to an out-of-plane wall collapse is a very common post-earthquake damage pattern. Numerical results showed that damage usually arises at the connection between walls but the simulation of the reduction of the wall-to-wall integrity appears not to have such a strong effect on the seismic capacity of the building when compared with other parameters [54].

Finally, the definition of the weights for the vulnerability index formulation adapted for vernacular architecture is finally based on the numerical results, using the correlation shown in Table 4 after the statistical analysis. The main idea behind the definition of a new SVIVA formulation was to use an analytical procedure in order to add robustness to existing formulations, which are traditionally based on empirical approaches and expert opinion. The expert opinions obtained are mainly intended to serve as a comparison, not to disregard its importance on the evaluation of the weights.

As a reference, the weights calculated numerically are compared with values proposed in the literature by other authors. Table 6 shows this comparison, acknowledging that the parameters are not exactly the same for all the methods, neither have the same exact physical meaning. There is an expected high variability among most of the weights, such as P4, P5 and P6. There is a noticeable disagreement in the case of wall openings (P7), which existing methods confer a minimal importance, but the parametric study proved that it can be a decisive parameter in some cases, particularly when coupled with rigid diaphragms [54]. Opposite to what was observed in Fig. 13 where the survey respondents did not consider much influential the type of material (P3), there is a general consensus among the methods in the literature on the importance of parameter P3, which particularly considers the mechanical properties and strength of the material. There is also agreement in giving moderate importance to the roof thrust (P6) and the previous structural damage in the building (P9). All methods also agree in conferring a reduced importance to the maximum wall span (P2).

\section{Seismic vulnerability index for vernacular architecture (SVIVA) formulation}

Table 7 shows the proposed final SVIVA vulnerability index formulation for vernacular architecture as the main outcome of the paper. Vulnerability index methods provide a measure of the lack of seismic safety of the buildings through a vulnerability index $\left(I_{V}\right)$. In the SVIVA case, the building is evaluated by providing a vulnerability class for each of the ten parameters. Four classes of increasing vulnerability are defined and associated with a qualification coefficient $\left(C_{v i}\right)$. Following

Table 6

Comparison among the parameters weights proposed by different authors.

\begin{tabular}{|c|c|c|c|c|c|c|}
\hline \multirow[b]{2}{*}{ Parameter } & \multicolumn{6}{|c|}{ Vulnerability index weight $\left(p_{i}\right)$} \\
\hline & Value adopted & Benedetti and Petrini [21] & Vicente [23] & Boukri and Bensaibi [36] & Ferreira $[65]$ & Shakya [33] \\
\hline P1: Wall slenderness & 1.00 & - & - & - & 0.50 & - \\
\hline P2: Maximum wall span & 0.50 & 0.25 & 0.50 & - & 0.50 & - \\
\hline P3: Type of material & 1.50 & 1.50 & 1.50 & 1.50 & 0.75 & 1.50 \\
\hline P4: Wall-to-wall connections & 0.75 & 1.00 & 1.00 & 1.00 & 0.50 & 1.50 \\
\hline P5: Horizontal diaphragms & 1.50 & 1.00 & 1.00 & 0.25 & 0.50 & 0.50 \\
\hline P6: Roof thrust & 0.50 & 1.00 & 1.00 & 0.25 & 0.50 & - \\
\hline P7: Wall openings & 1.50 & - & 0.50 & - & 0.50 & 1.00 \\
\hline P8: Number of floors & 1.50 & - & 1.50 & - & - & - \\
\hline P9: Previous structural damage & 0.75 & 1.00 & 1.00 & 1.00 & 0.75 & 1.00 \\
\hline P10: In-plane index & 0.50 & 0.50 & 0.75 & 0.50 & - & 1.00 \\
\hline
\end{tabular}


Table 7

Vulnerability index formulation for vernacular architecture.

\begin{tabular}{|c|c|c|c|c|c|c|}
\hline \multirow[t]{2}{*}{ Parameter } & \multicolumn{4}{|c|}{ Class $\left(\mathrm{C}_{\mathrm{vi}}\right)$} & \multirow[t]{2}{*}{ Weight $\left(p_{i}\right)$} & \multirow[t]{2}{*}{ Vulnerability index } \\
\hline & A & B & $\mathrm{C}$ & $\mathrm{D}$ & & \\
\hline P1. Wall slenderness & 0 & 5 & 20 & 50 & 1.00 & \multirow{4}{*}{$I_{V}=\sum_{i=1}^{10} C_{v i} \times p_{i}$} \\
\hline P2. Maximum wall span & 0 & 5 & 20 & 50 & 0.50 & \\
\hline P3. Type of material & 0 & 5 & 20 & 50 & 1.50 & \\
\hline $\begin{array}{l}\text { P4. Wall-to-wall } \\
\text { connections }\end{array}$ & 0 & 5 & 20 & 50 & 0.75 & \\
\hline P5. Horizontal diaphragms & 0 & 5 & 20 & 50 & 1.50 & \multirow[t]{3}{*}{$0 \leq I_{V} \leq 500$} \\
\hline P6. Roof thrust & 0 & 5 & 20 & 50 & 0.50 & \\
\hline P7. Wall openings & 0 & 5 & 20 & 50 & 1.50 & \\
\hline P8. Number of floors & 0 & 5 & 20 & 50 & 1.50 & \multirow{3}{*}{$\begin{array}{l}\text { Normalized index } \\
0 \leq I_{V} \leq 100\end{array}$} \\
\hline P9. State of conservation & 0 & 5 & 20 & 50 & 0.75 & \\
\hline P10. In-plane index & 0 & 5 & 20 & 50 & 0.50 & \\
\hline
\end{tabular}

the common vulnerability index formulations existing in the literature, the qualification coefficients are the same for all parameters. Thus, class A, related to the lowest vulnerability, has a qualification coefficient $\left(C_{v i}=0\right)$, while class D, related to the highest vulnerability has a qualification coefficient $\left(C_{v i}=50\right)$. Each parameter is also associated to a weight $\left(p_{i}\right)$, reflecting its relative importance and ranging from 0.5 for the least important to 1.5 for the most important ones. The vulnerability index $\left(I_{V}\right)$ is calculated as the weighted sum of ten parameters using the equation shown in Table 7. The value of $I_{V}$ ranges between 0 and 500 but, it is common, for ease of use, to normalize it to fall within a range between 0 (very low vulnerability) and 100 (very high). Ultimately, as previously discussed, using the approach proposed by Vicente [23] allows transforming the vulnerability index $\left(I_{V}\right)$ into the vulnerability index from the macroseismic method $(V)$. Then, the analytical expression from the macroseismic method (Eq. (1)) can be used to estimate the mean damage grade $\left(\mu_{D}\right)$ that the building would suffer for different seismic inputs and perform a complete seismic vulnerability and loss assessment.

\section{Conclusions}

The main objective of the present paper was to show the development of a new formulation for the seismic vulnerability index method that targets specifically vernacular architecture: the SVIVA formulation. Using the framework of vulnerability index methods, the SVIVA formulation is intended to be an expedited simplified approach. It provides the possibility of performing a primary seismic safety assessment by obtaining an indicator of the seismic performance of a building or group of buildings based on expedited surveys that can be carried out by means of simple visual inspection. As every vulnerability index method existing in the literature, it correlates the vulnerability of a structure with different parameters related to simple geometric and constructive characteristics.

The development of the proposed method was based on obtaining a comprehensive understanding of the seismic behavior of vernacular architecture, by means of detailed finite element modeling and nonlinear static analysis. The use of an analytical procedure to define the proposed vulnerability index formulation and the classes is considered as the main novelty of the present method and helps to strengthen the reliability of this simplified method, since existing formulations rely solely on empirical results obtained from post-earthquake surveys and expert judgment. A set of geometric, material and construction parameters were selected based on literature review and, according to those parameters, an extensive parametric study was performed to evaluate and quantify numerically their influence on the seismic performance of vernacular buildings. The influence of the different parameters was thus validated through numerical analysis and the results were used to provide a quantitative definition of four seismic vulnerability classes for each parameter. The vulnerability classes proposed are overall in line with the classifications available in the literature, but are adapted to the evaluation of the seismic vulnerability of vernacular buildings.

The completion of the vulnerability index formulation also required the determination of the parameters weights, which indicate the relative importance of each parameter in estimating the overall seismic vulnerability of the building. Two approaches were followed for the definition of the weights: (a) statistical; and (b) expert judgment. With respect to the statistical approach, all models built for the parametric analysis composed an extensive database that was used to perform a regression analysis. This allowed obtaining regression coefficients that were used to compare the relative importance of the parameters to estimate the seismic behavior of the models. These coefficients were then associated with the weights of the seismic vulnerability assessment parameters. The second approach was mostly intended to perceive the overall view of experts from different seismic prone regions throughout the world on the topic, and to compare their empirical judgment with the results obtained from the numerical campaign. The high scatter observed in their answers confirmed the difficulty of assessing the influence of the different parameters based only on expert judgment and post-earthquake damage observations. This fact also justified the use of an analytical-based approach for enhancing the comprehension of the contribution of the parameters to the structural response of vernacular buildings under seismic loading. In the end, a comparison between the weights obtained through the statistical and expert judgment approaches was provided and discussed. The final weights were also compared with the weights already used by similar methods available in the literature.

The results obtained highlighted the complexity of the matter and the difficulty to explain the seismic behavior of vernacular buildings only by considering the influence of ten independent parameters. The relationship between parameters is more complex than the one proposed by vulnerability index methods, where the influence of the parameters is considered individually. Nevertheless, the approach followed for the development of the SVIVA formulation was considered satisfactory, since the proposed seismic vulnerability assessment method is intended to be an easy-to-apply tool. Moreover, it also contributed to gain a better understanding of the structural behavior of many representative Portuguese vernacular architectural heritage typologies under seismic loading, acknowledging that Portuguese vernacular buildings share many characteristics with other vernacular constructions throughout the world. Thus, the results obtained in this work can also be representative for other similar structures outside Portugal.

\section{Acknowledgments}

The work presented in this paper was partly financed by FEDER funds through the Competitivity and Internationalization Operational Programme - COMPETE and by national funds through FCT Foundation for Science and Technology within the scope of the project POCI-01-01-0145-FEDER-007633.

\section{Appendix A}

See Table A1. 
Table A1

Seismic vulnerability classes proposed for the ten key parameters.

\begin{tabular}{cc}
\hline & P1. Wall slenderness $(\lambda)$ \\
\hline Class & Description \\
\hline A & $\lambda \leq 6$ \\
B & $6<\lambda \leq 9$ \\
C & $9<\lambda \leq 12$ \\
D & $\lambda>12$ \\
\hline
\end{tabular}

P2. Maximum wall span $\left(s_{\max }\right)$

\begin{tabular}{cc}
\hline Class & Description \\
\hline A & $s_{\max }<5$ \\
B & $5 \leq s_{\max }<7$ \\
C & $7 \leq s_{\max }<9$ \\
D & $s_{\max } \geq 9$ \\
\hline
\end{tabular}

P3. Type of material

\begin{tabular}{|c|c|c|c|c|}
\hline \multirow[b]{2}{*}{ Class } & \multirow[b]{2}{*}{ Description } & \multicolumn{3}{|c|}{ Reference material properties } \\
\hline & & $E(\mathrm{MPa})$ & $f_{c}(\mathrm{MPa})$ & $f_{t}(\mathrm{MPa})$ \\
\hline A & $\begin{array}{l}\text { Stone masonry consisting of well-cut homogeneous units in terms of material and } \\
\text { dimensions with parallelepiped shape. Carefully worked horizontal courses with not- } \\
\text { aligned mortar head joints. The mortar has good quality and properly fills vertical and } \\
\text { horizontal joints. Proper transversal connection among wall leaves using through- } \\
\text { stones or stones/fired clay brick bands through the wall thickness. Fired clay brick } \\
\text { masonry with well-arranged vertical and horizontal joints and good quality mortar }\end{array}$ & $2000-3000$ & $2-4$ & 0.1-0.6 \\
\hline B & $\begin{array}{l}\text { Non-homogeneous stone masonry in terms of materials and dimensions but well- } \\
\text { arranged longitudinally and transversally respecting horizontal courses, not-aligned } \\
\text { mortar head joints and good quality mortar. Proper transversal connection among wall } \\
\text { leaves using through-stones or stone/fired clay brick bands through the wall thickness. } \\
\text { Fired clay brick masonry with well-arranged joints and average quality mortar }\end{array}$ & $1500-2000$ & $1.5-2$ & $0.1-0.4$ \\
\hline $\mathrm{C}$ & $\begin{array}{l}\text { Coarsely carved stone masonry irregularly shaped with poor arrangement of the } \\
\text { stones and weak or average quality mortar. Few or no transversal connection } \\
\text { elements. The core of multiple-leaf walls has a reasonable consistency }\end{array}$ & $1000-1500$ & $1-1.5$ & $0.05-0.3$ \\
\hline $\mathrm{D}$ & $\begin{array}{l}\text { Irregular not worked stone masonry of low quality, with not respected horizontal } \\
\text { courses or aligned mortar head joints. Poor quality mortar. There are no transversal } \\
\text { connection elements. Multi-leaf masonry with partially unstable empty core showing } \\
\text { voids. Adobe masonry and rammed earth walls are also included within this class }\end{array}$ & $150-1000$ & $0.6-1.5$ & $0.05-02$ \\
\hline
\end{tabular}

\begin{tabular}{|c|c|}
\hline \multicolumn{2}{|r|}{ P4. Wall-to-wall connections } \\
\hline Class & Description \\
\hline A & $\begin{array}{l}\text { All wall-to-wall connections are workmanlike built. There is no weakening signs or construction deficiencies. In case of } \\
\text { masonry buildings, there is a good interlocking between the masonry units at the corners. In case of earthen buildings, there are } \\
\text { no vertical joints at the corners }\end{array}$ \\
\hline B & $\begin{array}{l}\text { Some wall-to-wall connections show either construction deficiencies, such as lack of efficient interlocking of the masonry units } \\
\text { in case of masonry buildings or vertical joints in case of earthen construction, or weakening signs }\end{array}$ \\
\hline C & $\begin{array}{l}\text { Many wall-to-wall connections are deficient or degraded because of construction deficiencies, such as vertical joints, and/or } \\
\text { weakening signs, such as cracks or detachments }\end{array}$ \\
\hline $\mathrm{D}$ & $\begin{array}{l}\text { Most wall-to-wall connections are barely non-existent because of poor construction practices or are highly degraded with } \\
\text { important signs of separation and vertical cracks }\end{array}$ \\
\hline
\end{tabular}




\begin{tabular}{|c|c|c|c|c|}
\hline \multicolumn{5}{|c|}{ P5. Horizontal diaphragms } \\
\hline Class & Description & $\begin{array}{l}\text { Beam-to-wall } \\
\text { connection }\end{array}$ & $\begin{array}{l}\text { Diaphragm } \\
\text { connection }\end{array}$ & $\begin{array}{l}\text { Diaphragm } \\
\text { stiffness }\end{array}$ \\
\hline A & Rigid diaphragm well-connected to the walls & Good & Good & Rigid \\
\hline \multirow{3}{*}{ B } & $\begin{array}{l}\text { Flexible diaphragm well-connected to the walls. Rigid diaphragm well- } \\
\text { connected to the walls but beams poorly coupled with the walls. Rigid }\end{array}$ & Good & Good & Flexible \\
\hline & $\begin{array}{l}\text { diaphragm poorly connected to the walls but beams properly coupled with the } \\
\text { walls. Poor connections can be either due to construction deficiencies or }\end{array}$ & Poor & Good & Rigid \\
\hline & $\begin{array}{l}\text { because of signs of deterioration and decay of the timber elements, such as } \\
\text { rotting or biological attacks }\end{array}$ & Good & Poor & Rigid \\
\hline \multirow{5}{*}{ C } & Flexible diaphragm well-connected to the walls but beams poorly coupled & Poor & Good & Flexible \\
\hline & & Poor & Poor & Rigid \\
\hline & $\begin{array}{l}\text { connected to the walls but beams properly coupled with the walls. } \\
\text { Diaphragms of negligible stiffness with beams well-connected to the walls }\end{array}$ & Good & Poor & Flexible \\
\hline & achieving a coupling effect. Poor connections can be either due to & Poor & Poor & Flexible \\
\hline & $\begin{array}{l}\text { construction deficiencies or because of signs of deterioration and decay of the } \\
\text { timber elements, such as rotting or biological attacks }\end{array}$ & Good & - & - \\
\hline D & $\begin{array}{l}\text { Diaphragms of negligible stiffness with beams poorly connected to the walls. } \\
\text { Poor connections can be either due to construction deficiencies or because of } \\
\text { signs of deterioration and decay of the timber elements, such as rotting or } \\
\text { biological attacks }\end{array}$ & Poor & - & - \\
\hline
\end{tabular}

\section{P6. Roof thrust}

\begin{tabular}{cl}
\hline Class & \multicolumn{1}{c}{ Description } \\
\hline A & Non-thrusting roof types and semi-thrusting roof types with light-weight and high inclination \\
B & $\begin{array}{l}\text { Thrusting roof types with light-weight }\left(\mathrm{w}<0.9 \mathrm{kN} / \mathrm{m}^{2}\right) \text { and high inclination }\left(\alpha>35^{\circ}\right) \text {. Semi-thrusting roof types with light- } \\
\text { weight and low inclination }\left(\alpha<20^{\circ}\right) \text { or heavy roof types }\left(\mathrm{w}>0.9 \mathrm{kN} / \mathrm{m}^{2}\right) \text { with high inclination }\left(\alpha>35^{\circ}\right)\end{array}$ \\
& $\begin{array}{l}\text { Thrusting roof types with light-weight }\left(\mathrm{w}<0.9 \mathrm{kN} / \mathrm{m}^{2}\right) \text { and medium inclination }\left(20^{\circ}<\alpha<35^{\circ}\right) \text { or heavy roof types }(\mathrm{w}>0.9 \\
\left.\mathrm{kN} / \mathrm{m}^{2}\right) \text { with high inclination }\left(\alpha>35^{\circ}\right) . \text { Semi-thrusting heavy roof types }\left(\mathrm{w}>0.9 \mathrm{kN} / \mathrm{m}^{2}\right) \text { with medium-high inclination }\left(20^{\circ}<\right. \\
\\
\text { C }\end{array} \quad \begin{array}{l}\left.\alpha<35^{\circ}\right) \\
\text { D }\end{array}$ \\
$\begin{array}{l}\text { Thrusting roof types with light-weight }\left(\mathrm{w}<0.9 \mathrm{kN} / \mathrm{m}^{2}\right) \text { and low inclination }\left(\alpha<20^{\circ}\right) \text { or heavy roof types }\left(\mathrm{w}>0.9 \mathrm{kN} / \mathrm{m}^{2}\right) \text { with } \\
\text { medium-high inclination }\left(\alpha<35^{\circ}\right)\end{array}$
\end{tabular}

P7. Wall openings (IP)

\begin{tabular}{cc}
\hline Class & Description \\
\hline A & $I P<10 \%$ \\
B & $10 \% \leq I P<25 \%$ \\
C & $25 \% \leq I P<40 \%$ \\
D & $I P \geq 40 \%$ \\
\hline
\end{tabular}

\section{P8. Number of floors}

\begin{tabular}{cc}
\hline Class & Description \\
\hline A & 1 floor \\
B & - \\
C & 2 floors \\
D & $\geq 3$ floors \\
\hline
\end{tabular}




\section{P9. Previous structural damage}

\begin{tabular}{|c|c|}
\hline Class & Description \\
\hline A & Structural load bearing walls are in good condition with no visible damage \\
\hline B & $\begin{array}{l}\text { Structural load bearing walls present hairline and small cracks }(\approx 1 \mathrm{~mm} \text { or less) that are not widespread, and/or slight signs of } \\
\text { deformation in the structural elements (drifts below } 0.1 \%)\end{array}$ \\
\hline $\mathrm{C}$ & $\begin{array}{l}\text { Structural load bearing walls present a poor state of conservation showing moderate cracks }(\approx 1-5 \mathrm{~mm}) \text { and/or relevant signs of } \\
\text { deformation in the structural elements (drifts between } 0.1-0.5 \% \text { ) }\end{array}$ \\
\hline $\mathrm{D}$ & $\begin{array}{l}\text { Structural load bearing walls present a state of severe deterioration with widespread damage. There are large structurally } \\
\text { compromising cracks }(>5 \mathrm{~mm} \text { ) at critical locations, such as near the corners, indicating a sign of disconnection between } \\
\text { orthogonal walls. There are severe signs of deformation in the structural elements, such as out-of-plumb walls or bulging of the } \\
\text { load bearing walls (drifts over } 0.5 \% \text { ) }\end{array}$ \\
\hline
\end{tabular}

P10. In-plane index $\left(\gamma_{i}\right)$

\begin{tabular}{cc}
\hline Class & Description \\
\hline A & $\gamma_{i} \geq 0.65$ \\
B & $0.55 \leq \gamma_{i}<0.65$ \\
C & $0.45 \leq \gamma_{i}<0.55$ \\
D & $\gamma_{i}<0.45$ \\
\hline
\end{tabular}

\section{References}

[1] Fernandes J, Mateus R. Energy efficiency principles in Portuguese vernacular architecture. In: Proc of international conference BSA, Porto, Portugal; 2012.

[2] Correia M. Experiences from past for today's challenges, in: The road to sustainable development. Traditional and generational change, La fábrica, Fundación Contemporánea, Madrid, Spain; 2017 [chapter 6].

[3] Vasconcelos G, Lourenço PB. Experimental characterization of stone masonry in shear and compression. Constr Build Mater 2009;23(11):3337-45.

[4] Vasconcelos G, Lourenço PB. In-plane experimental behavior of stone masonry walls. J Struct Eng (ASCE) 2009;135(10):1269-78.

[5] Varum H, Figueiredo A, Silveira D, Martins T, Costa A. Outputs from the research developed at the university of Aveiro regarding the mechanical characterization of existing adobe constructions in Portugal. Revista Informes de la Construcción 2011;63(523):127-42.

[6] Miccoli L, Oliveira DV, Silva R, Müller U, Schueremans L. Static behaviour of rammed earth: experimental testing and finite element modelling. Mater Struct 2014;48(10):3443-56.

[7] Miccoli L, Drougkas A, Müller U. In-plane behaviour of rammed earth under cycling loading: experimental testing and finite element modelling. Eng Struct 2016;125:144-52.

[8] Aktas YD. Seismic resistance of traditional timber-frame Himis structures in Turkey: a brief overview. Int Wood Prod J 2017;8:21-8.

[9] Preti M, Neffati M, Bolis V. Earthen masonry infill walls: use of wooden boards as sliding joints for seismic resistance. Constr Build Mater 2018;184:100-10.

[10] Neves F, Costa A, Vicente R, Oliveira CS, Varum H. Seismic vulnerability assessment and characterization of the buildings on Faial Island, Azores. Bull Earthq Eng 2012;10(1):27-44.

[11] Sorrentino L, Liberatore L, Liberatore D, Masiani R. The behaviour of vernaculat buildings in the 2012 Emilia earthquakes. Bull Earthq Eng 2013;12(5):2367-82.

[12] Sayin E, Yön B, Calayir Y, Karaton M. Failures of masonry and adobe buildings during the June 23, 2011 Maden-(Elazig) earthquake in Turkey. Eng Fail Anal 2013;34:779-91.

[13] Gautam D, Prajapati J, Paterno KV, Bhetwal KK, Neupane P. Disaster resilient vernacular housing technology in Nepal. Geoenviron Disast 2016;3(1).

[14] D’Ayala D. Correlation of fragility curves for vernacular building types: houses in Lalitpur, Nepal and Istanbul, Turkey. In: Proc of the 13th world conference on earthquake engineering, Vancouver BC Canada; 2004.

[15] Barros R, Rodrigues H, Varum H, Costa A, Correia M. Seismic analysis of a Portuguese vernacular building. J Archit Eng 2017;24(1).

[16] Carabbio R, Pieraccini L, Silvestri S, Schildkamp M. How can vernacular construction techniques sustain earthquakes: the case of the Bhatar buildings. Front Built Environ 2018;4:18.

[17] Ortega J, Vasconcelos G, Rodrigues H, Correia M. Assessment of the influence of horizontal diaphragms on the seismic performance of vernacular buildings. Bull Earthq Eng 2018.

[18] Kouris L. Seismic fragility curves for timber-framed masonry structures based on empirical damage data. Int J Sustain Mater Struct Syst 2016;2:233-49.

[19] Gautam D, Rodrigues H. Seismic vulnerability of urban vernacular buildings in Nepal: case of Newari Construction. J Earthquake Eng 2018.
[20] Rosti A, Rota M, Penna A. Damage classification and derivation of damage probability matrices from L'Aquila (2009) post-earthquake survey data. Bull Earthq Eng 2018;16(9):3687-720.

[21] Benedetti D, Petrini V.Sulla Vulnerabilità Di Edifici in Muratura: Proposta Di Un Metodo Di Valutazione, L'industria delle Costruzioni 1984;149(1): 66-74.

[22] Coburn AW, Spence RJS, Pomonis A. Vulnerability and risk assessment, Disaster Management Training Programme (DMTP) of the United Nations Development Programme (UNPD). Cambridge, U.K.: Cambridge Architectural Research Limited; 1994.

[23] Vicente R. Estratégias e metodologias para intervenções de reabilitação urbana. Avaliação da vulnerabilidade e do risco sísmico do edificado da Baixa de Coimbra, Ph.D. thesis. Aveiro, Portugal: Universidade do Aveiro; 2008.

[24] Calvi GM, Pinho R, Magenes G, Bommer JJ, Restrepo-Vélez LF, Crowley H. Development of seismic vulnerability assessment methodologies over the past 30 years. ISET J Earthq Technol 2006;34(472):75-104.

[25] Jaiswal K, Aspinall W, Perkins D, Wald D, Porter KA. Use of expert judgement to estimate seismic vulnerability of selected building types. In: Proc of 15th world conference on earthquake engineering, Lisbon, Portugal; 2012

[26] ATC-13. Earthquake damage evaluation data for California, Applied Technology Council (ATC), Redwood City, California, USA; 1985.

[27] HAZUS. HAZUS earthquake loss estimation methodology: technical manual, Vol. 1, Federal Emergency Management Agency (FEMA), Washington D.C., USA; 1999.

[28] Giovinazzi S, Lagomarsino S. A macroseismic model for the vulnerability assessment of buildings. In: Proc of 13th world conference on earthquake engineering Vancouver BC, Canada; 2004

[29] Barbat A, Eeri M, Yépez Moya F, Canas JA. Damage scenarios simulation for seismic risk assessment in urban zones. Earthq Spectra 1996;12(3):371-94.

[30] Vicente R, Parodi S, Lagomarsino S, Varum H, Mendes da Silva JAR. Seismic vulnerability and risk assessment: a case study of the historic city centre of Coimbra, Portugal. Bull Earthq Eng 2011;9(4):1067-96.

[31] Ferreira TM, Vicente R, Mendes da Silva JAR, Varum H, Costa A. Seismic vulnerability assessment of historical urban centres: case study of the old city centre in Seixal Portugal. Bull Earthq Eng 2013;11(5):1753-73.

[32] Ferreira TM, Maio R, Vicente R. Seismic vulnerability assessment of the old city centre of Horta, Azores: calibration and application of a seismic vulnerability index method. Bull Earthq Eng 2017;15(7):2879-99.

[33] Shakya M. Seismic vulnerability assessment of slender masonry structures Ph.D. thesis Portugal: Universidade de Aveiro, Aveiro; 2014.

[34] GNDT. Scheda di esposizione e vulnerabilità e di rilevamento danni di primo livello e secondo livello (muratura e cemento armato), GNDT (Italian Group for the Defense against Earthquakes), Rome, Italy; 1994.

[35] Sepe V, Speranza E, Viskovic A. A method for large-scale vulnerability assessment of historic towers. J Struct Control Health Monit 2008;15:389-415.

[36] Boukri M, Bensaibi M. Vulnerability index of Algiers Masonry buildings. In: Proc of 14th world conference on earthquake engineering, Beijing, China; 2008.

[37] Ferreira TM, Vicente R, Varum H. Seismic vulnerability assessment of masonry facade walls: development, application and validation of a new scoring method. Struct Eng Mech 2014;50(4):541-61.

[38] Blondet M, Villa García GM, Brzev S, Rubiños A. Earthquake-resistant construction of adobe buildings: a tutorial. Oakland, California, USA: Earthquake Engineering 
Research Institute (EERI); 2011.

[39] Bothara J, Brzev S. A tutorial: improving the seismic performance of stone masonry buildings. Oakland, California, USA: Earthquake Engineering Research Institute (EERI); 2012.

[40] Ortega J, Vasconcelos G, Rodrigues H, Correia M, Lourenço PB. Traditional earthquake resistant techniques for vernacular architecture and local seismic cultures: a literature review. J Cult Herit 2017;27:181-96.

[41] Correia M. A habitação vernácula rural no Alentejo, Portugal, in: Memorias del IV Seminario Iberoamericano sobre vivienda rural y calidad de vida en los asentamientos rurales, Santiago del Chile, Chile; 2002.

[42] Correia M. Taipa no Alentejo. Lisboa, Portugal: Argumentum; 2007.

[43] Spence RJS, D'Ayala D. Damage assessment and analysis of the 1997 UmbriaMarche earthquakes. Struct Eng Int 1999;9(3):229-33.

[44] Lourenço PB, Oliveira DV, Leite JC, Ingham JM, Modena C, Porto F. Simplified indexes for the seismic assessment of masonry buildings: International database and validation. Eng Fail Anal 2013;34:585-605.

[45] Giuffrè. Sicurezza en conservazione dei centri storici: Il caso Ortigia, Editrice Laterza, Bari, Italy; 1993.

[46] Binda L, Penazzi D. Classification of masonry cross sections and of typologies of historic buildings, Technical Report, Book of Commission RILEM MMM; 2000.

[47] Binda L, Saisi A. State of the Art of Research on Historic Structures in Italy, Department of Structural Engineering, Politecnico di Milano, Milan, Italy; 2001.

[48] NTC. Norme Tecniche per le Costruzioni. D.M. 14 gennaio 2008, S.O. No. 30, G.U. No. 29/2008, Rome, Italy; 2008.

[49] Tarque N. Seismic risk assessment of adobe dwellings, M.Sc. thesis, Università degli Studi di Padova, Padua, Italy; 2008.

[50] Gallego R, Arto I. Evaluation of seismic behaviour of rammed earth structures. In: Mileto Vegas, Soriano, Cristinieditors. Earthen architecture: past, present and future. London, UK: Taylor \& Francis Group; 2014.

[51] Angulo-Ibáñez Q, Mas-Tomás Á, Galvañ-Llopis V, Sántolaria-Montesinos JL. Traditional braces of earth constructions. Constr Build Mater 2012;30:389-99.

[52] Mendes N, Lourenço PB. Seismic vulnerability of existing masonry buildings: nonlinear parametric analysis. In: Psycharis, Pantazopoulou, Papadrakakis, editors. Seismic assessment, behavior and retrofit of heritage buildings and monuments. Computational methods in applied sciences, vol. 37, Springer; 2015.

[53] Masciotta MG, Ramos LF, Lourenço PB, Matos JAC. Development of key performance indicators for the structural assessment of heritage buildings. In: Proc of 8th European workshop on structural health monitoring (EWSHM 2016), Bilbao, Spain; 2016.

[54] Ortega J. Reduction of the seismic vulnerability of vernacular architecture with traditional strengthening solutions Ph.D. thesis Portugal: Universidade do Minho, Guimarães; 2018.

[55] TNO. DIsplacement method ANAlyser. User's manual, release 9.4.4., Netherlands;
2011.

[56] Lourenço PB, Krakowiak F, Fernandes FM, Ramos LF. Failure analysis of Monastery of Jerónimos, Lisbon: how to learn from sophisticated numerical models. Eng Fail Anal 2007;14:280-300.

[57] Lourenço PB, Karanikoloudis G, Mendes N, Corallo C. Assessment of the South aisle in Canterbury. In: Proc of the 2nd international conference on preservation, maintenance and rehabilition of historical buildings and structures, Porto, Portugal; 2015.

[58] Lourenço PB, Karanikoloudis G, Greco F. In situ testing and modeling of cultural heritage buildings in Peru. In: Proc. of the 10th International conference on structural analysis of historical constructions (SAHC 2016), Leuven, Belgium; 2016.

[59] Lourenço PB. Recent advances in masonry structures: micromodelling and homogenization. In: GalvanettoAliabadi Ferri, editors. Multiscale modeling in solid mechanics: computational approaches. London, UK: Imperial College Press; 2009. p. 280-300.

[60] Gomes MI, Lopes M, de Brito J. Seismic resistance of earth construction in Portugal. Eng Struct 2011;33(3):932-41.

[61] Lourenço PB, Mendes N, Ramos LF, Oliveira DV. Analysis of masonry structures without box-behavior. Int J Architect Heritage Conserv Anal Restor 2011;5(4-5):369-82.

[62] Rota M, Penna A, Magenes G. A methodology for deriving analytical fragility curves for masonry buildings based on stochastic nonlinear analyses. Eng Struct 2010;32:1312-23.

[63] Ferreira TM, Vicente R, Varum H, Costa A, Costa AA. Out-of-plane seismic response of stone masonry walls: experimental and analytical study of real piers. In: Proc of the 15th world conference on earthquake engineering, Lisbon, Portugal; 2012.

[64] Mouyiannou A, Rota M, Penna A, Magenes G. Identification of suitable limit states from nonlinear dynamic analyses of masonry structures. J Earthq Eng 2014;18(2):231-63.

[65] R Development Core Team. R: A language and environment for statistical computing, R Foundation for Statistical Computing, Vienna, Austria; 2008.

[66] Ferreira TM. Avaliação da vulnerabilidade sísmica das paredes de fachada de edifícios em alvenaria M.Sc. thesis Aveiro, Portugal: Universidade de Aveiro; 2009.

[67] Saaty RW. The analytic hierarchy process - what it is and how it is used. Math Model 1987;9(3-5):161-76.

[68] Liu YC, Chen CS. A new approach for application of rock mass classification on rock slope stability assessment. Eng Geol 2007;89(1-2):129-43.

[69] Pinheiro M, Sanches S, Miranda T, Neves A, Tinoco J, Ferreira A, et al. A new empirical system for rock slope stability analysis in exploitation stage. Int J Rock Mech Min Sci 2015;76:182-91.

[70] Harker PT. Incomplete pairwise comparisons in the analytic hierarchy process. Math Model 1987;9(11):837-48. 